\title{
ESCENIFICACIONES DE LA HIBRIDEZ EN EL DISCURSO DE LA CONQUISTA. ANALOGÍA Y COMPARACIÓN COMO ESTRATEGIAS TRANSLATOLÓGICAS PARA LA CONSTRUCCIÓN DE LA OTREDAD*
}

\section{AlFonso DE TORO*}

\section{RESUMEN}

El ensayo tiene como objetivo demostrar en base a diversas teorías poscoloniales y postmodernas que el Descubrimiento y la Conquista de América fue un gigantesco proceso de 'translación' antropológico, etnológico, filosófico, cultural, religioso, artístico, económico, histórico... en el cual los españoles, por una parte, crean una nueva cultura y civilización y son los verdaderos iniciadores de la Epoca Moderna (ampliando así las tesis de Elliot y haciendo una fuerte crítica Greenblatt), y, por otra, inician un largo y duro proceso híbrido de la construcción del otro que se encuentra más allá de la propia intención y voluntad. Se muestra cómo los procesos de hibridación se sitúan en las estrategias de la retórica, de lo gestual, de lo pictórico y de lo icónico, por ejemplo, en la H istoria verdadera dela Conquista de Nueva España (1568) de Bernal Díaz del Castillo o en la iconografía tlaxcalteca sobre la Malinche.

Palabras claves: Escenificación, hibridez, analogía, estrategias translatológicas, construcciones de la otredad.

\section{ABSTRACT}

Using diverse post-modern and post-colonial theories, the present essay aims to examine how the Discovery and the Conquest of America was an anthropological, ethnological, philosophical, cultural, religious, artistic, economical, and historical gigantic'translation' process. On the one hand, the Spaniards create a new culture and civilisation and are the true initiators of the Modern Age (expanding the theses of Elliot and criticizing those of Greenblatt). On the other hand, the Spaniards are caught up in a long and difficult process of hybridization leading to the construction of the Other, a process that takes place beyond their will or intention. We show how these hybrid processes operate

* Dr. en Filosofía. Profesor Ibero-Amerikanisches Forschungsseminar/Universität Leipzig, Alemania. E-mail: rz.uni-leipzig.d 
in strategies of rhetoric, gesture, iconography and arts; for example, in the Historia verdadera de la Conquista de Nueva España (1568) of Bernal Díaz del Castillo or in the Malinche-iconography of the tlaxcaltecas.

Keywords: Performance, hybridity, analogy, translatological strategies, constructions of Otherness,

Recibido: 05.01.2006. Aceptado: 12.05.2006.

\begin{abstract}
“'Ma c'ubab tha' quiere decir: 'No entendemos vuestras palabras', lo que los españoles transforman en 'Yucatán' y le dan el nombre a la provincia" (Rincón 1990: 221)

"Nor is this a matter for surprise, for the attempt of one society to comprehend another inevitably forces it to reappraise itself” (Elliot 1970: 14)
\end{abstract}

\title{
1. OBSERVACIONES PRELIMINARES
}

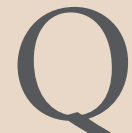

UISIERAMOS comenzar por aclarar el término 'translación' que preferimos al de 'traducción', ya que este último se emplea primordialmente en los estudios de traducción sui generis. No es una casualidad que el original Instituto de Interpretación y Traducción en Leipzig se llame hoy en día Instituto de Translatología y Lingüística y que vaya a tener un Máster de Translatología junto con el de Traducción e Interpretación. La razón es que el término de translatología tiene una extensión mucho más amplia que el de traducción, subsume los conceptos de traducción e interpretación, y focaliza en forma particular y central el aspecto cultural de la traducción. Por esto entendemos el término de translatología como un proceso complejo cultural, medial, social y pragmasemiótico. Así, el término de 'translación' abarca tanto los campos de la antropología, la etnología, la filosofía, la historia, los medios de comunicación como los de la gestualidad, el cuerpo y diversos sistemas discursivos. Mi preferencia por el término translación no menoscaba en ningún modo el uso alternativo de 'traducción'. Al fin la terminología no se basa en ontologías, sino en predicadores lógicosemánticos que dependiendo de las definiciones cambian su significado tradicional.

En todo caso, dentro de mi concepción, el acto o estrategia translatológico pone de manifiesto la 'transformación' y recodificación de la enunciación que transporta sistemas culturales (lengua, códigos como religión, costumbres, saber, organización social, naturaleza, etc.), de donde nace un nuevo sistema cultural que se concretiza en un proceso semiótico de codificación, decodificación y recodificación, de deterritorialización y reterritorialización, de producción y de escenificación con nuevas 'funciones'. Y aquí es donde yace el criterio más importante del acto de translación. 
El proceso de translación -como proceso híbrido en sí- incluye por cierto la transmedialidad y no tan sólo el acto de producción y recepción, sino también el de la inscripción de una mediación o trasfiguración en el acto de translación con una finalidad determinada. Además, el acto de translación es en su totalidad un proceso de escenificación basado en sus constituyentes tales como la representación, la imagen, la escritura, el gesto...

Bajo escenificación no entendemos solamente la representación o concretización mediática de procesos de comunicación, sino a la vez aquello que queremos llamar plotting o 'diegetización' de lo representado, es decir, la remodelación de episodios en una acción coherente como se da, por ejemplo, en los cronistas del Descubrimiento y de la Conquista o en los historiadores del siglo XIX (por ejemplo en Prescott). En estos textos contamos con una teatralización/escenificación de parlamentos y acciones de los personajes que a su vez son refuncionalizados dramáticamente (como en las Cartas de Cortés o en la Historia verdadera de la Conquista de la Nueva España (1568) de Bernal Díaz del Castillo).

Translación significa en nuestro contexto Pasajes dela otredad tanto como resultado de la observación y percepción de encuentros entre diversas culturas, etnias, religiones y sistemas del conocimiento y del saber, como así también de la producción de discursos que forman un conocimiento determinado que llevan a la construcción de lo 'propio' y de lo 'extraño' concerniente, por ejemplo, al conquistado y al conquistador.

\section{FINALIDADES}

Mi tema de hoy es doble: el historiar y con ello deslimitar históricamente el concepto de hibridez y demostrar que el Descubrimiento y la Conquista están enmarcados en un gigantesco proceso de comunicación o translación $y$, como tal, constituyen desde un comienzo un involuntario thirth space en el cual inevitablemente los signos intercambiados son traducidos, transformados, reapropiados, retorizados, reescritos, releídos y reescuchados: oído, vista, gesto y cuerpo son partes constitutivas de este acto de comunicación, de un acto de enunciación entrecruzado por la diferencia inscrita ontológicamente en el acto de enunciación mismo (Lacan), produciendo así un discurso deterritorializado y disjunto que es, además, el resultado de todo tipo de enunciación entendida como 'desapropiación' ('Entäußerung').

Tan sólo si comprendemos y aceptamos que todo tipo de comunicación o translación está construido por la representación de enunciados y sistemas culturales, y que está constituyéndose continuamente en un espacio nuevo, contradictorio y ambivalente, esto es, híbrido, entonces podemos constatar que la reclamada jerarquía y la ceguera cultural de una cultura dominante basada en una 'pureza cultural y étnica' es imposible de sostener

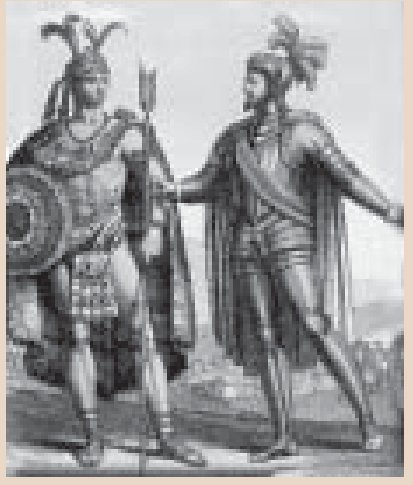

Cortés y Moctezuma

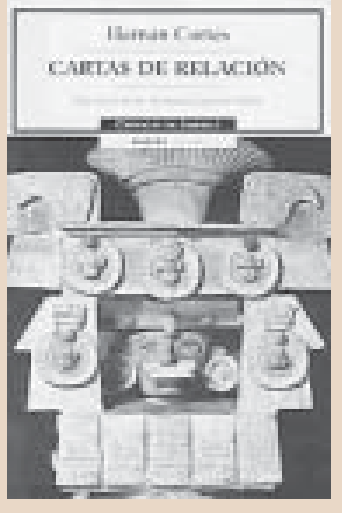




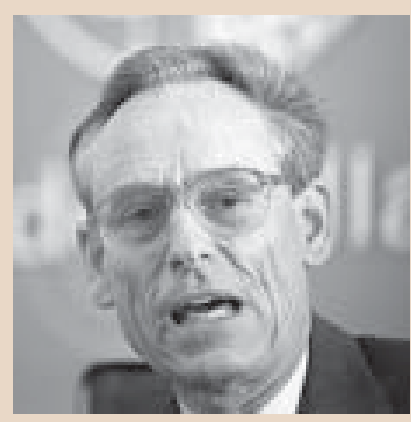

J. Elliot

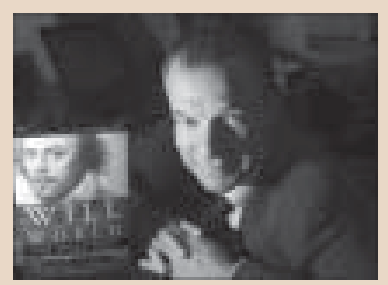

S. Greenblatt y de afirmar que la cultura sometida sea solamente víctima de donde nada nuevo nace.

Quisiera hoy pues continuar con mi tarea comenzada precisamente en una sección del pasado congreso de Hispanistas Alemanes en Ratisbona ("Hybriditätsdiskurse in Lateinamerika: Von der Eroberung bis zum 21. Jahrhundert") y en las Ringvorlesungen en el Centro Iberoamericano de Investigación de Leipzig en el semestre de verano de 2003 y de 2004, donde también participaron los colegas, entre otros, Vittora Borsò y Michael Rössner, también ahora presentes.

La construcción de lo 'propio' y de lo 'extraño' ha sido en los cronistas de la Conquista como un complejo proceso de translación desatendido por la investigación -con la relativa excepción de Elliot (1970) y de Todorov (1982)en cuanto la facticidad de la destrucción de las culturas precolombinas cubrió el nivel de la representación y construcción del otro y del yo. Subirats (1994) representa la corriente que sostiene que el Descubrimiento y la Conquista se reducen a la codicia y evangelización por parte de los españoles, y en aras de éstos, a una mera destrucción. Subirats comparte con Todorov la opinión de que lo sucedido en América solamente puede ser denominado como el genocidio más grande en la historia de la humanidad. Sin embargo, Todorov sabe ver y describir la incipiente construcción de ese espacio intermedio como producto de la translación, algo que ya había adelantado Elliot. Greenblatt representa, como veremos, una línea similar, la de Subirats respecto a la incapacidad de los españoles de captar y digerir la otredad, planteada como un objeto deseado pero imposible de poseer, lo que impulsa a los españoles a la destrucción de Tenochtitlán como medio de compensación para satisfacer así ese deseo insaciable. Los investigadores, como los españoles en su tiempo, se han resistido a ver ese espacio intermedio, ya sea por las razones dadas o por la supuesta superioridad de la tradición humanista española de corte helénico latino y cristiano como nos los presenta Maravall (1966). Resumiendo: el complejo y largo proceso de hibridación (que es siempre un proceso de translación), como consecuencia del Descubrimiento y de la Conquista, fue oprimido a raíz de la focalización de muchas investigaciones en la destrucción y eliminación de los indios y su cultura, a raíz de la indignación moral y, finalmente, a razón de ideologías tales como las posiciones esencialistas en Latinoamérica o hegemónicas en Europa. Los unos reclaman la cultura precolombina como la base de la identidad de Latinoamérica generando un discurso de lo 'propio', los otros sostienen que los europeos solamente proyectaron sus normas en el nuevo mundo produciendo un discurso de su propia superioridad. Los primeros arriesgan dejar a Latinoamérica fuera del discurso histórico, los segundos la reducen al mero campo de experimentación europea, esto es, al campo de lo epígono. 
Para poder describir el proceso de translación y de hibridación de la construcción de la otredad en los escritos de la Conquista hago hincapié en la necesidad de distinguir entre un nivel del acaecer deloshechos empíricos y de la representación de estos hechos: los españoles negaron a los indígenas en palabra y hecho la razón de ser cualquier traza de ser humano, negándoles la legitimación de la categoría 'ser humano' y, recordemos el debate de Las Casas contra Sepúlveda en el que este último argumenta con Aristóteles frente a Carlos V sobre si el predicado 'ser humano' es aplicable o no a los indios. Las Casas vence en esta primera batalla, pero poco o nada cambia en la mentalidad de la gran mayoría de los conquistadores. Naturalmente que nadie niega la destrucción casi total de los indios a través de guerras, enfermedades y explotación, la destrucción de sus templos, de sus dioses y de su organización socioeconómica. Pero sobre la base de la distinción propuesta podemos observar que paralelamente al proceso de destrucción se genera un discurso de la otredad a través de la descripción de este violento y destructivo encuentro. Un gran número de cronistas no consigue legitimar el discurso de la Conquista, éste se les escapa de su control, se les escurre generando una hibridación incipiente y, con ello, la construcción del otro y de sí mismo.

Mi propósito radica en describir y demostrar los procesos de translación/hibridación y escenificación que se encuentran más allá delo teleológico, más allá de un proceso consciente $\mathrm{o}$ intencional, un proceso asimétrico e indeterminado ya que difícilmente escuchamos la voz de los indígenas, poco sabemos de sus sentimientos y situación psicológica, a no ser en casos excepcionales y altamente mediatizados, escenificados. Pero sobre la base de las obras de Acosta, Alva Ixtlixóchitls, Bernal Díaz del Castillo, Durán, el Inca Garcilaso de la Vega, Guamán Poma de Ayala, Landa, Las Casas, Núñez Cabeza de Vaca, Sahagún, Santa Cruz Pachacuti, Zorita, entre tantos otros, podemos percibir la voz indígena y constatar que el proceso de hibridación se da en el ejercicio de la religión, en la vida cotidiana y en el lenguaje. Tanto los indios como los españoles viven en los intersticios, en las intersecciones aunque en diversos grados.

Intento emprender un camino ya iniciado por Albert Memmi en su Portrait du colonisateur précédé du Portrait du colonisé (1957), por Elliot en The Old World and the New (1970), por Said en Orientalism (1978), por Todorov en La Conquête de l'Amérique (1982), por Abdelkebir Khatibi en M aghreb Pluriel (1983) y por Carlos Fuentes en En esto creo (2002), que nos ponen un instrumentario, a disposición para analizar como los cronistas en el acto descriptivo y de percepción comienzan a abandonar sus estructuras mentales occidentales ya que su conocimiento y su lengua no les permite aprehender lo observado y experimentado con lo cual se les escapa la intención de un discurso y escenificación prefigurados, apareciendo así estructu-
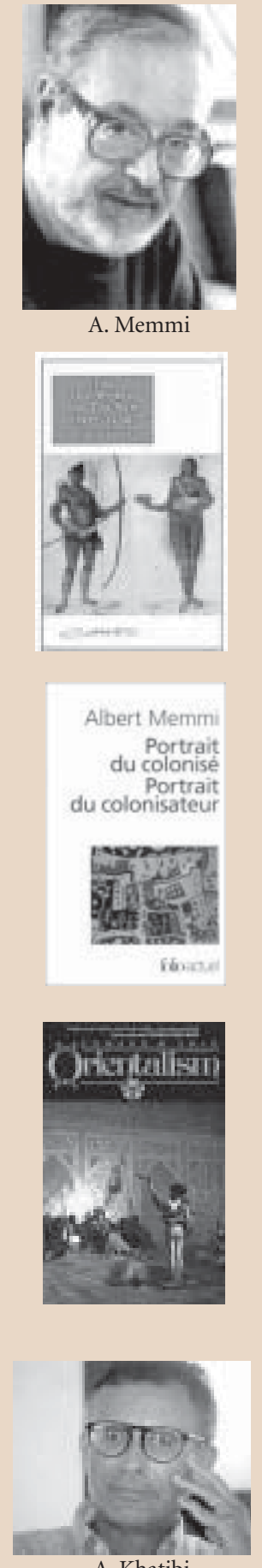

A. Khatibi 


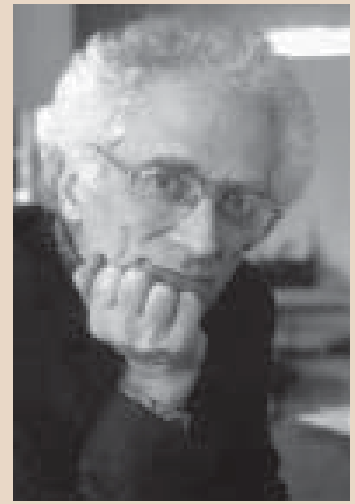

T. Todorov ras híbridas. Bajo escenificación entendemos en primer lugar el intento de los cronistas de visualizar lo observado para describirlo en toda su magnitud, para hacerlo accesible y, en segundo, el recurso a procedimientos retórico-discursivos tales como comparación, metáfora, analogía y equivalencia, intertextualidad y diversas estrategias textuales y de suspenso narrativo. El resultado no es una simple descripción de lo real, sino una sofisticada escenificación de lo real.

En la tradición de $\mathrm{H}$. White, en la cual también se sitúa Todorov, quisiera advertir que mi interés en la descripción de formas de escenificación como resultado de procesos translatológicos -de donde se desprende la hibridez-, no radica en la constatación de la facticidad, en la veracidad o en la probabilidad de los sucesos descritos, ya que la mayoría de éstos no se pueden probar empíricamente, con lo cual no quiero tampoco clasificarlos como 'ficcionales', algo que tampoco representaría mayor problema ya que Aristóteles, al parecer, distinguió clarividentemente lo empírico de lo representacional en cuanto calificó al arte con mayor valor que lo meramente factible: "quamorem et res magis philosophica et melior poesis est quam historia: man poesis magis universalia, historia magis singularia dicit" (1451b, 5$7 ; 159)$. Pero por eso la poesía (poiesis) es más filosófica y elevada que la historia, pues la poesía dice más bien lo general (ta kathólu), y la historia lo particular (ta kath'hékaston) (1451b, 5-7;158). Mi interés radica en las prácticas gestuales y escenográficas.

Mi aproximación tampoco se basa en los grand récit que, rechazados por la Escuela de los Anales, ya habían caído mucho antes de que Lyotard lo anunciara. Me baso en aquella infinidad de petites histoires que principalmente construyen y constituyen lo histórico, lo que Deleuze denomina histoires mineures. En el sentido que Foucault le da al término de tradición discursiva, de discontinuidad de lo discursivo, me interesa no lo que se dice, sino cómo se dice y escenifica lo dicho, lo que se configura detrás de la palabra y que revela la escenificación. Esta es otra definición de translación cultural en nuestro contexto. Lo significativo no es el nivel del enunciado, sino de la enunciación, no el del inventio, sino el del elocutio como se formula en la retórica antigua. Lo principal es que algo se dice/representa sin evaluar si lo dicho o representado es falso o verdadero. Lo importante es que es parte de una red representacional de una época y cultura:

Le seul remède est de ne pas lire ces textes comme des énoncés transparents, mais d'essayer en même temps de tenir compte de l'acte et des circonstances de leur énonciation. Quant à la justification, elle pourrait s'exprimer dans le langage des anciens théoriciens: les questions soulevées ici renvoient moins à une connaissance du vrai qu'à celle du vraisemblable. Je m'explique: un fait a pu ne pas avoir lieu, contrairement aux allégations de tel chroniqueur. Mais que celui-ci ait pu l'affirmer, 
qu'il ait pu compter sur son acceptation par le public contemporain est au moins aussi révélateur que la simple occurrence d'un événement, laquelle relève après tout du hasard. La réception des énoncés est plus révélatrice pour l'histoire des idéologies que ne l'est leur production; et lorsqu'un auteur se trompe ou ment, son texte n'est pas moins significatif que quand il dit vrai ; l'important est que le texte soit recevable par les contemporains, ou qu'il ait été cru tel par son producteur. De ce point de vue, la notion de "faux" est non pertinente (Todorov 1982: 60).

Carlos Fuentes en El naranjo pone en boca de Jerónimo de Aguilar las sentencias:

Me pregunto si un evento que no es narrado, ocurre en realidad. Pues lo que no se inventa, sólo se consigna. Algo más: una catástrofe (y toda guerra lo es) sólo es disputada si es narrada. La narración la sobrepasa. La narración disputa el orden de las cosas. El silencio lo confirma (Fuentes 1993: 58).

Por esto, los hechos no tienen vida en sí, sino que su representación y escenificación escritural es lo que los hace pasar a ser parte de la realidad: lo representado es pues lo real.

En vez de dedicarnos a la improductiva e ingrata tarea de investigar si un hecho ocurrió o no como ha sido representado, más satisfactorio y alentador es la investigación de las representaciones en un micronivel -en el interior de cada texto-y en un macronivel, es decir, en la comparación de diversos textos y autores sobre un objeto determinado. Estos niveles forman parte de esa red de translación. Por ejemplo, las representaciones de Bernal Díaz del Castillo vs. López de Gómara vs. Cortés vs. Sahagún compiten en el transcurso histórico unas con otras.

En su trabajo, Todorov hace un aporte considerable al problema mencionado y no se contenta tan sólo con su indignación moral ("mon intérêt principal est moins celui d'un historien que d'un moraliste" / "le plus grand génocide de l'histoire de l'humanité". 1982: 12). Muy por el contrario: Todorov da un primer paso en la distinción entre el nivel de los hechos y de su representación, cuando distingue entre un "niveau axiologique" y un "niveau pratique" (Todorov 1982: 191). Además, analiza los textos bajo el aspecto de la hibridez aun cuando no emplee este termino, sino los usuales en la teoría francesa, el de altérité y el de métissage que tienen la misma extensión e intención que el de hibridez. Asimismo recurre a términos tales como 'paradoja' o a conceptos de la psicología como son los de "dédoublement de la personnalité" (Todorov 1982: 208), "l'ambigu” o "le contradictoire" (Todorov 1982: 223) y destaca el momento de la oscilación o ambivalencia en la perspectiva de los cronistas. Por esto considero el libro de Todorov un trabajo realmente fundador de un nuevo tipo de interpretación de las crónicas.

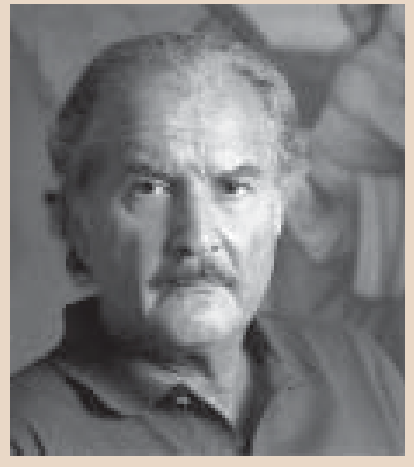

C. Fuentes 


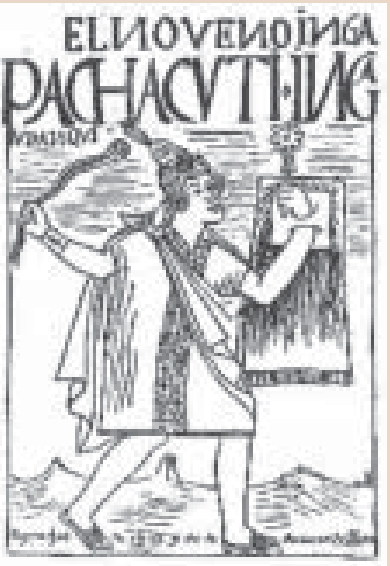

Ya podemos adelantar que la opresión, la destrucción física y epistemológica de los indígenas va preñada con la construcción de un Nuevo Mundo, con lo cual la cruzada civilizadora de España se diferencia en forma fundamental de la británica y francesa.

Concebimos las representaciones discursivas como testimonios o confesiones históricos donde los cronistas alegan narrar solamente la verdad de lo ocurrido. Importantes son las diversas estrategias de perspectiva narrativa, particularmente aquellas narraciones 'desde abajo' de los habitantes de la periferia, como son los casos de Bernal Díaz, de Alvar Núñez, de Guamán Poma de Ayala, de Juan Santa Cruz Pachacuti y, en parte, de la escenificación de una situación periférica del Inca Garcilaso. El cambio de perspectiva tiene un papel fundamental en la translación y en los procesos de hibridación que construyen el otro y el mismo.

\section{HIBRIDEZ COMO CATEGORIA ANALITICA, COMO REPRESENTACION Y FUNDAMENTO DEL PENSAMIENTO HISTORICO}

Hibridez es un fenómeno general que se origina -como habíamos apuntado más arriba- en la articulación de un acto de enunciación en cuanto ésta adquiere su propia autonomía y energía en una continua proliferación en el contacto con otras enunciaciones. Este hecho tiene consecuencias decisivas para la relación entre lo 'propio' y lo 'extraño', así para el término cultura e identidad, ya que no se revelan ni como unidad constituidos por una lógica binaria dentro de un concepto humanístico del 'nostrum' ni tampoco son parte de una relativismo cultural según la premisa: "we place ourselves in the position of the other", como indica Bhabha, sino como un acto translatológico en un tercer espacio de enunciación híbrido. Dentro del contexto del Descubrimiento y de la Conquista se potencia esta situación comunicativa por la diferencia de culturas y lenguas. Se producen disrupciones, o como lo formula Bhabha, "[The] split space of enunciation may open the way to conceptualizing an inter-national culture, based not on the exoticism or multi-culturalism of the diversity of cultures, but on the inscription and articulation of culture's hybridity", $y$ " [...] the 'inter' -is the cutting edge of translation and negotiation, the in- between, the space of the entre that Derrida has opened up in writing itself- that carries the burden of the meaning of culture" y además:

It is in this space that we will find those words with which we can speak of Ourselves and Other. And by exploring this hybridity, this 'Third Space', we may elude the politics of polarity and emerge as the others of ourselves (Bhabha 1994: 209). 
Hibridez como fenómeno de translación por excelencia, como el lugar de los márgenes intersectivos donde se generan deterritorializaciones y reterritorializaciones, recodifiaciones y reinvenciones. De esta forma se va creando otra lógica, de la suplementariedad, de la no simultaneidad de lo simultáneo (Rincón).

\section{REPRESENTACIONES HIBRIDAS Y ESCENIFICACIONES DE LA OTREDAD EN LA INVESTIGACIÓN ACTUAL}

Nos preguntamos, frente al contexto propuesto, si el Descubrimiento y la Conquista de América se pueden reducir solamente a una topografía de proyección de los españoles a raíz de la pérdida de sus utopías, de sus deseos insatisfechos, de modo que ellos vean en América un nuevo Paraíso o Epoca de Oro y así la posibilidad de realizar el verdadero cristianismo (Joachim de Floris, Rincón). ¿ Son las lecturas, descripciones y representaciones tan sólo productos normativos y prefigurados que permanecen dentro del contexto hispano-europeo-cristiano? ¿O no producen el Descubrimiento y la Conquista de América más bien un discurso híbrido que se escapa del control de su enunciante formando una compleja red en la que quedan atrapados los conquistadores como los conquistados, codificando una nueva cultura?

Carlos Rincón se manifiesta en los años '90 muy escéptico en relación con este acto de translación en cuanto niega a los españoles y europeos la capacidad de captar y asumir la otredad, aun cuando reconoce que nuevas teorías hayan posibilitado "nuevas formulaciones de las relaciones con respecto al otro" (Rincón 1990: 221), lo cual nos permite, con un nuevo instrumentario, interpretar las crónicas de otra forma. Sin embargo, la tesis central de Carlos Rincón (1990: 221,224) es que en el debate y descripción de la Otredad tanto Las Casas como su adversario Sepúlveda -como Montaigne en sus ensayos "Des Coches" y "Des Cannibales" (Essays, vol. III)- desarrollan un discurso etnocéntrico sobre las prácticas indígenas que lleva a una crítica interna del fracaso de las propias instituciones, a un debate de sus propios problemas y la creación de nuevas utopías y a idealizaciones de tipo exotizantes, pero no a una verdadera construcción del otro, ya que todos estos discursos estaban sometidos al dictado de expansión imperial y del cristianismo. Rincón (1990: 221, 224) describe la incapacidad de los españoles de aprender lo 'extraño' basándose en algunos ejemplos provenientes de Elliot y a raíz de que los españoles, como los demás europeos, partían de un conocimiento de la cartografía del mundo de Strabon, Ptolomeo y Pomponio Mela (Rincón 1990: 222), en donde reinaba la perfecta y natural ignorancia de un mundo que se estaba recién descubriendo y que, no obstante, no cambiaron la cartografía hasta mucho más tarde. La actitud de los españoles, sostiene Rincón, documenta el fracaso de una oportunidad que

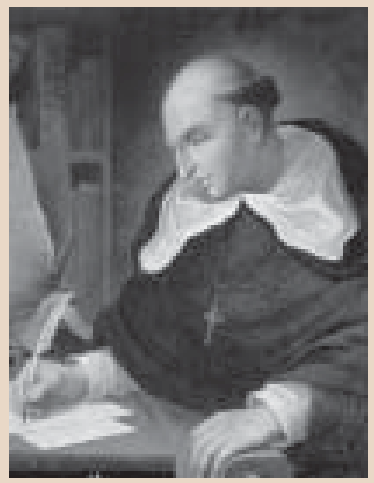

B. de las Casas

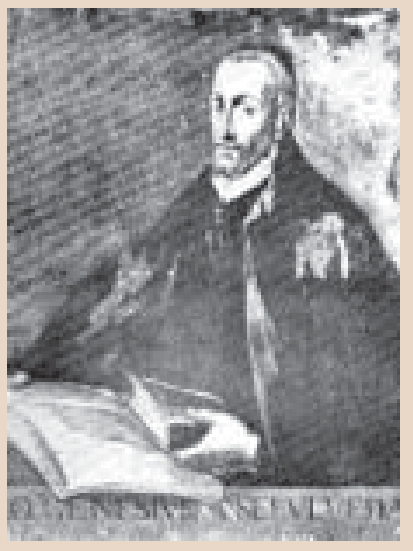

G. de Sepúlveda 

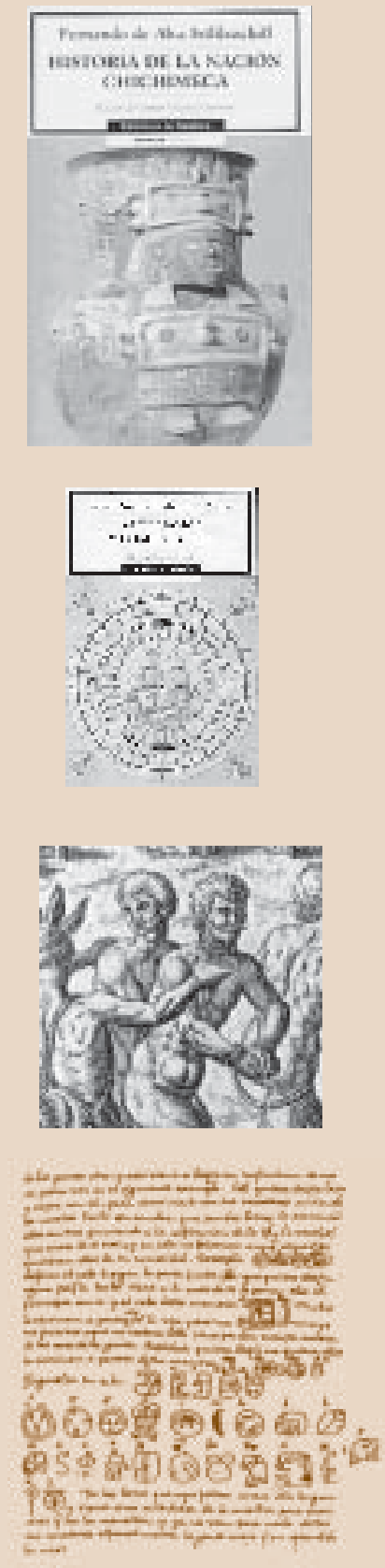

hubiera podido crear otra versión del mundo (al contrario de Gewecke 1986: 226 en sus pertinentes observaciones), el "conflictivo encuentro [...] no se emplea como punto de partida de un radical cuestionamiento" de Europa, donde se define al indígena según los parámetros de lo que significa civilización en una incipiente modernidad: medios de producción, alto desarrollo de la escritura, arte y ciencia, de la organización social y económica y poder militar (con estos criterios se evaluará, a partir de ese momento a Latinoamérica, en particular frente al desarrollo que más tarde tomará el capitalismo protestante en Estados Unidos) o se acusa los abusos y crueldades de los españoles, pero no existe ninguna reflexión sobre el nuevo mundo en sí. Por esto, para Rincón representan "la forzada introducción de lo europeo y la absorción de la formas culturales indígenas [...] dos caras de una misma medalla" (Rincón 1990: 230). Naturalmente que las consideraciones de Carlos Rincón son válidas para un gran número de escritos, quizás para la mayoría, y Subirats (1994) y Greenblatt (de este último nos ocuparemos en el curso del trabajo) parecen confirmar esta posición. Pero, a pesar de todo, en estos escritos se inscribe la ambivalencia impuesta por el lugar y la cultura encontrando ambas posiciones: la construcción etnocéntrica y la construcción de la otredad, que muchas veces queda encubierta por los métodos de descripción de la analogía, similitud, pero que a la vez son fuente del descubrimiento de la otredad, así en las obras de Las Casas, Alonzo de Zorita, H istoria de la Nueva España, Fernando de Alva Ixtlixóchitl, Historia dela nación chichimeca, Diego Durán, Historia de las Indias de Nueva España e islas de Tierra Firme, Diego de Landa, Relación de las cosas de Yucatán, Alvar Núñez Cabeza de Vaca, Naufragios, Bernal Díaz del Castillo, H istoria verdadera de la Conquista de la Nueva España.

Elliot muestra en forma maestra cómo una vez superado el impacto traumático del Descubrimiento los europeos comienzan a cristalizar un nuevo pensamiento en la segunda parte del siglo XVI después de casi un siglo de digerir el acontecimiento.

Un hecho evidente es que los españoles naturalmente observan, perciben y describen desde su sistema normativo, ¿desde cuál otro podían partir? Debemos apuntar que los españoles, como los europeos, no disponían en aquel tiempo del instrumentario para confrontar la otredad en un territorio que ni siquiera existía en la cartografía de la época. Fuera de eso, los españoles disponían de malas condiciones para captar, entender y aceptar el Nuevo Mundo, ya que se estaban deshaciendo de la cultura judeomusulmana, y a pesar de que ésta les era conocida y familiar desde hacía siglos, pasaban sin intermedio a una cultura absolutamente extraña, donde los seres humanos no sólo andaban desnudos, sino que adoraban ídolos a los que les inmolaban víctimas humanas e incluso se realizaban prácticas de canibalismo dentro de rituales religiosos. Rincón (1990: 229) considera esta problemática agudamente como anteriormente Elliot en su diferenciada y erudita publicación. 


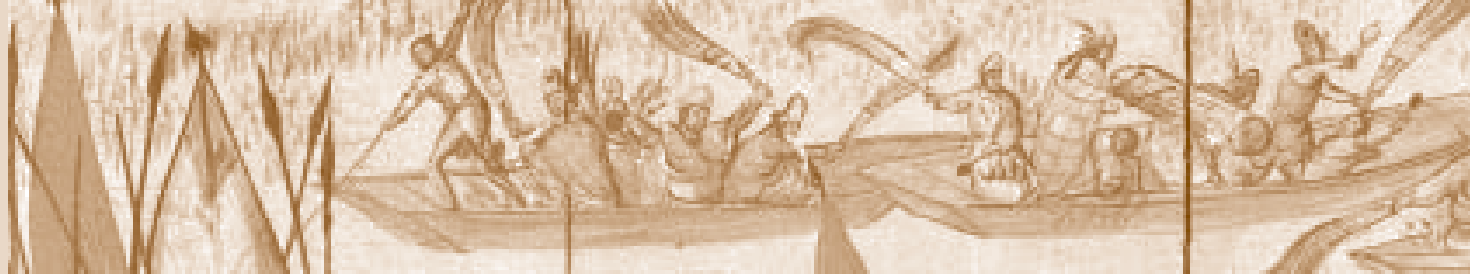

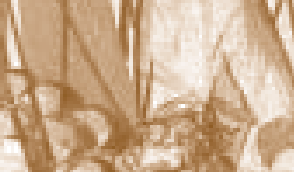

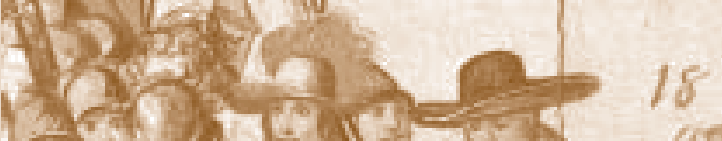

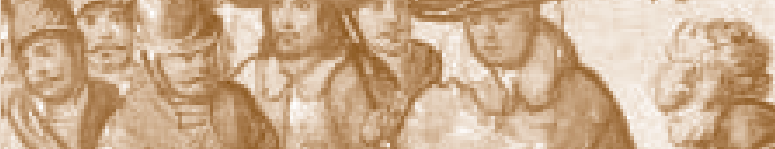

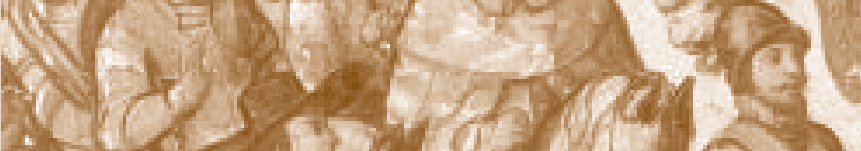

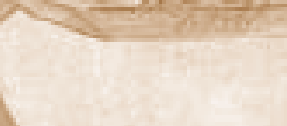

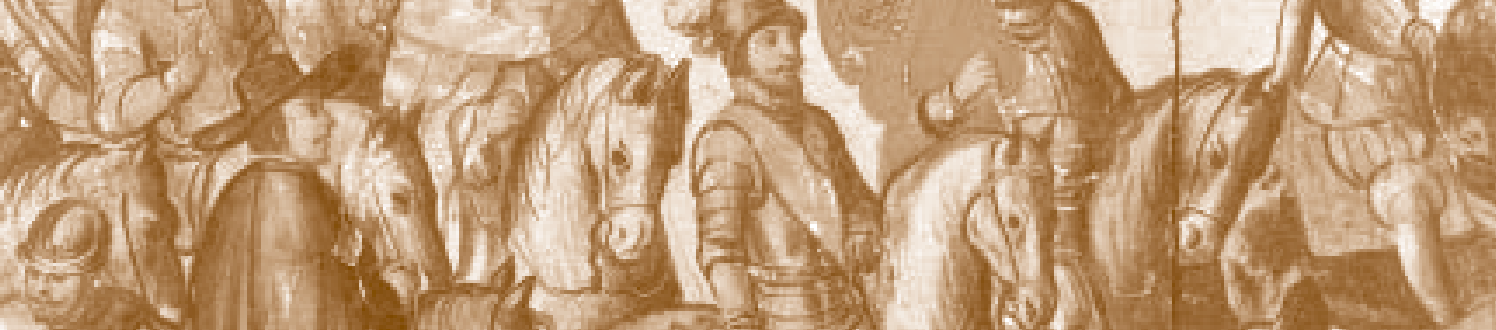

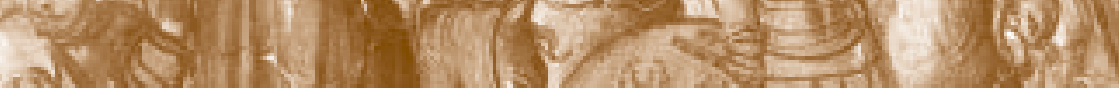

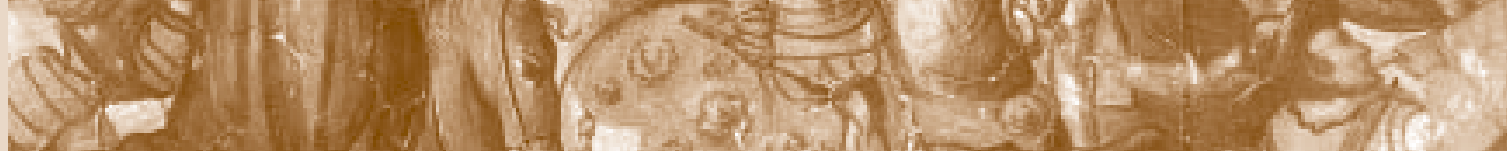

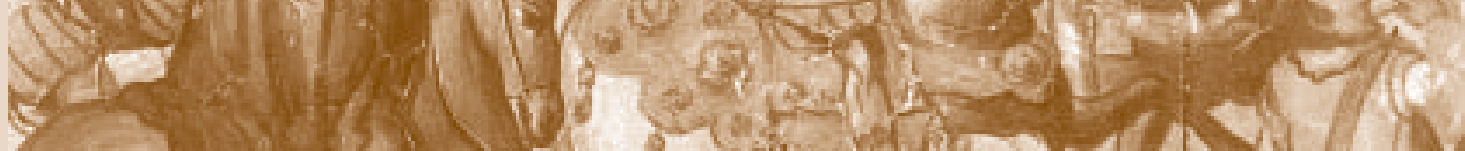

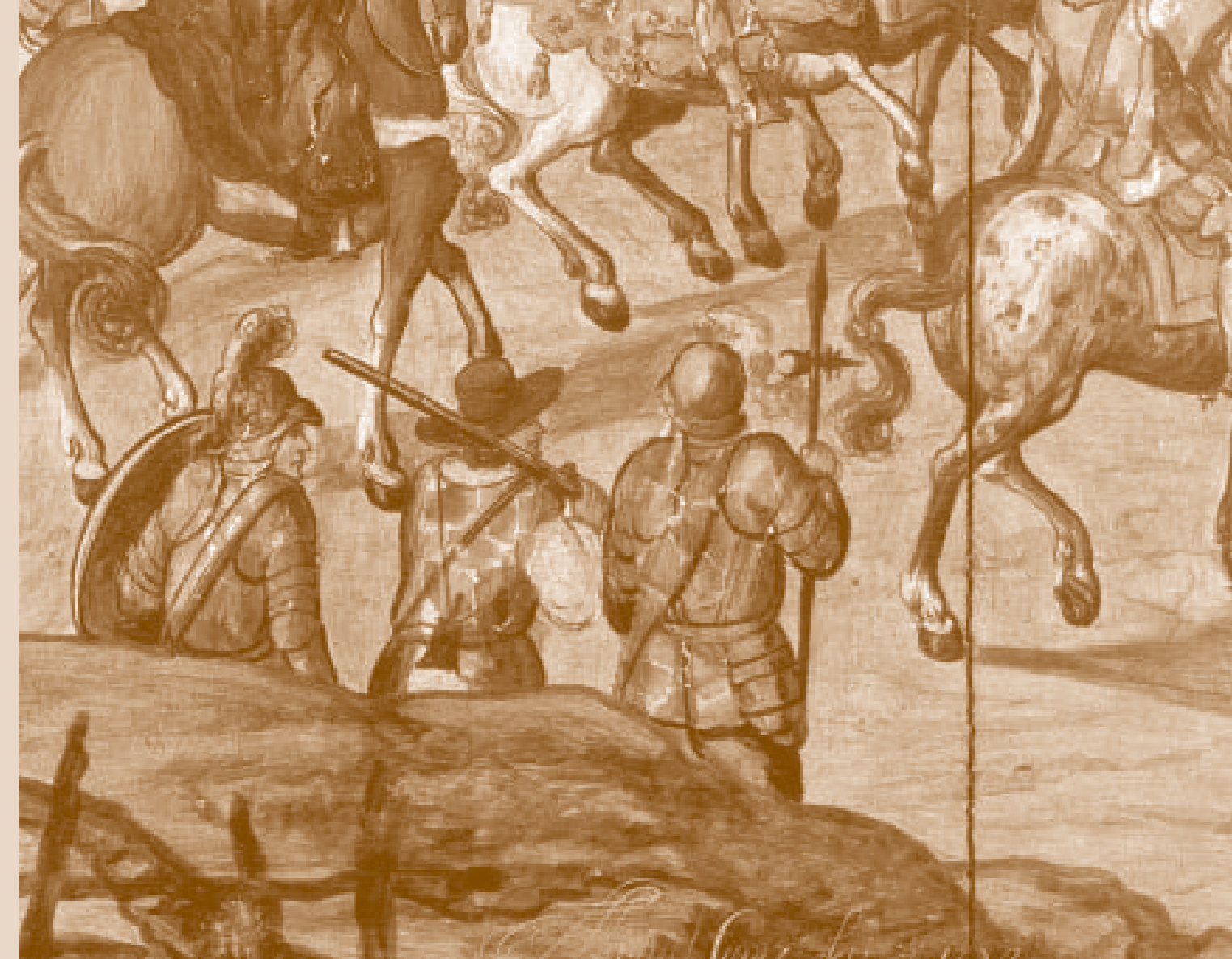

Primera entrada de Cortés y sus tropas en Tenochtitlán (Museo de América, Madrid). 
Los españoles no desperdiciaron en su totalidad la oportunidad de aceptar la otredad en América, como con la expulsión de los musulmanes y judíos en 1492 que fue, por lo demás, una empresa europea, en la que España se decidió por Europa y por construir una raza "limpia de sangre". Por ello no debe sorprendernos que los españoles percibieran el Descubrimiento y la Conquista de América como una nueva cruzada.

Y a pesar de todo, el problemático encuentro no estuvo totalmente dominado por la evangelización y codicia, sino también por curiosidad, por elementos sociales y el deseo de conocimiento, como indica Elliot (1970). El problema fundamental del Descubrimiento y de la Conquista es el choque de dos culturas que se distinguían radicalmente en sus formas de comunicación. Los actores Moctezuma y Cortés personifican estas formas de comunicación: una dialogizante con los dioses como lo indican Hugh (1993/2000) y Todorov (1982) o una comunicación interior y dialogizante con la naturaleza y con un presente eterno como lo narra Saer en El entenado, y otra abierta y pragmática.

Carlos Fuentes describe un aspecto en El naranjo basándose en la Conquista de México, que también es válido para toda la Conquista de América y que muestra cómo ésta es el resultado de un complejísimo y laborioso acto de comunicación cultural sin código común que se realiza en un duro y penoso acto de translación y en una negociación permanente. Mientras los aztecas -(cfr. Todorov (1982) más abajo y Hugh (1993/2000)- hablan con los dioses y de ellos esperan obtener respuestas para su conducta, los españoles se comunican en una forma interpersonal, hablan con individuos. La casta dirigente y el pueblo de los aztecas estaban dominados por las profecías divinas y por un mundo en su consumación, los españoles, por el contrario, estaban dominados por la precoz idea renacentista de un mundo dinámico proyectado hacia el futuro. Los aztecas estaban a la espera de señales para codificar el mundo y los españoles atribuían u ofrecían los resultados de sus actos a Dios. Carlos Fuentes, como Bernal Díaz, muestran cómo el poder radica principalmente en el dominio del código lingüístico y cultural y en la capacidad y habilidad de "traducir" de Jerónimo de Aguilar y, muy particularmente, de la Malinche. Se trata en un principio de un acto de translación descentrado, que pasa a través del Náhuatl y del Maya al español, luego directamente del Náhuatl al español. Igualmente se trata de una comunicación que se sitúa en un espacio o cartografía intermedia y que se manifiesta en la imposibilidad de almacenar y de transmitir numerosas y diversas informaciones, es decir, de un nuevo e inconcebible mundo-como indica Carlos Rincón (1990: 222) en consenso con J. H. Elliot (1970/1992: 1, 19)-, un mundo tan nuevo para los españoles que no sabían dónde se encontraban (el narrador en Cien años de soledad de García Márquez dice que "el mundo era tan nuevo que a las cosas había que señalarlas con el dedo") y de pronto también tan diferente para los aztecas. Translación y recepción exigen de los españoles lo que no pueden rendir ni abarcar: 


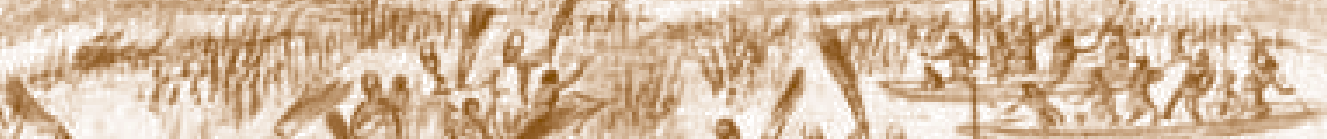

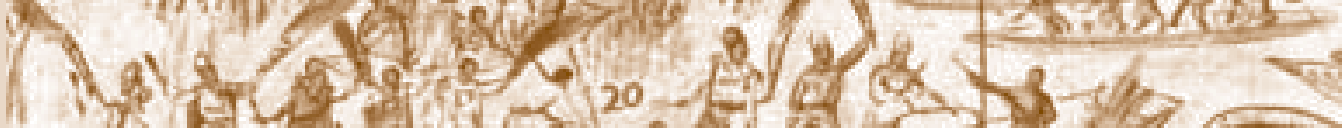

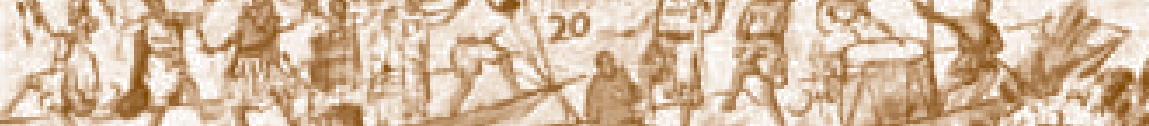

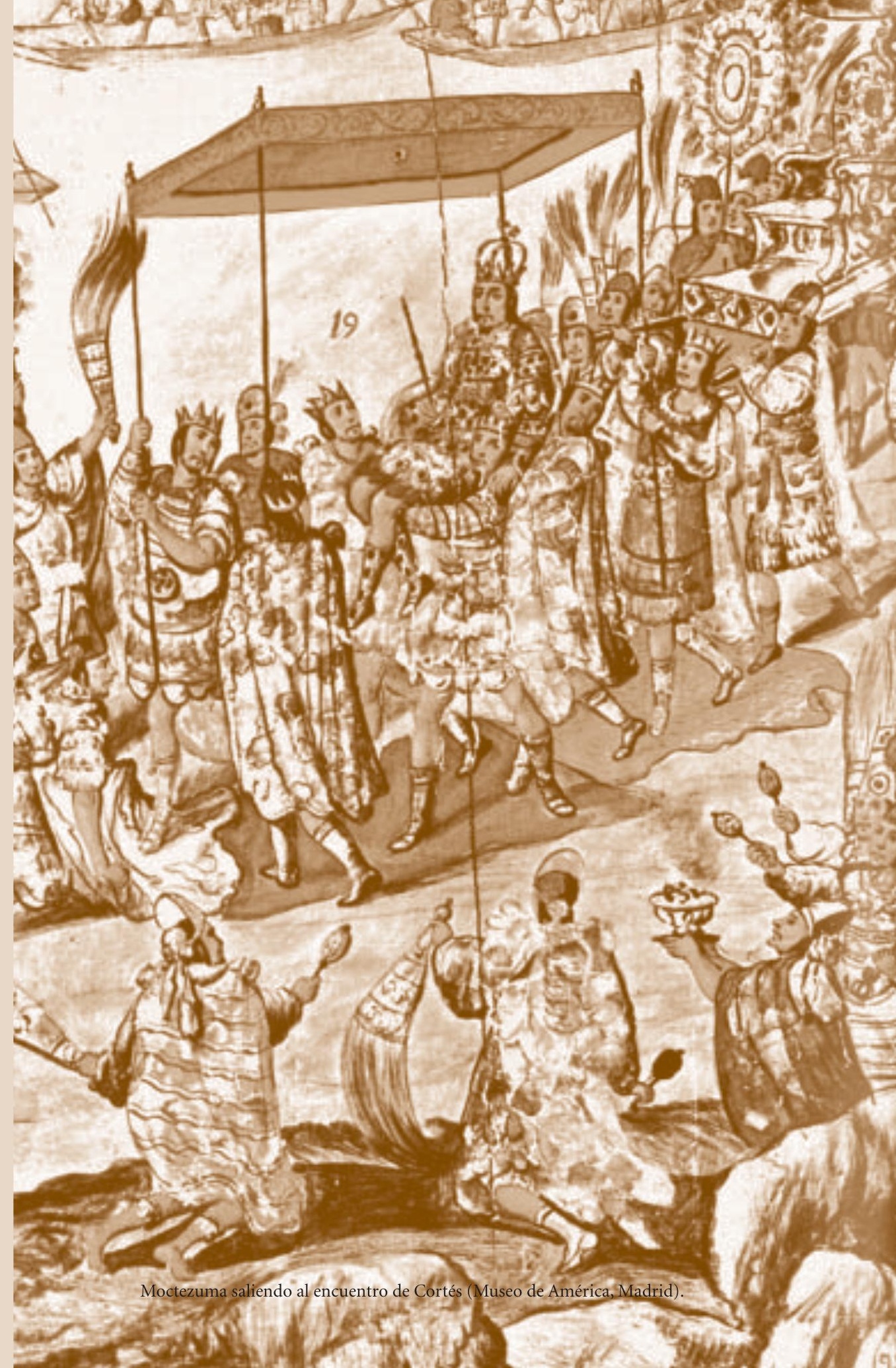


[...] as if, at a certain point, the mental shutters come down; as if, with so much to see and absorb and understand, the effort suddenly becomes too much for them, and Europeans retreat to the half-light of their traditional mental world (Elliot 1970: 14).

Aun cuando sea aparentemente evidente que los europeos en los siglos XVI y XVII perciben lo extraño a través de su sistema normativo (otra vez, ¿desde dónde si no del suyo?, lo cual continuará siendo así hasta hoy en día), a pesar de que las idealizaciones y proyecciones de recuperar un paraíso perdido no se cumplen y de que su capacidad de percepción y de descripción topan rápidamente con sus límites; a pesar de que, por ejemplo, Pérez de Oliva en 1528 escriba que Colón había hecho su segundo viaje para modelar a los indios según la imagen de los españoles y de que para la mayoría de lo percibido faltaran las palabras y éstas debieran ser creadas, no es menos cierto que en el camino de la 'observación', 'descripción', de la 'mediación'/'translación' y del 'entendimiento', los cronistas estaban obligados en forma diferente a abandonarse a lo extraño, ya que de otra forma no habría translación posible, no habría aprehensión; ésta solamente puede ser almacenada en la memoria a través de su estructuración, mediación oral, escrita, pictográfica u otra. Con ello, se moviliza un proceso irreversible, obligado, imperativamente de la construcción de lo extraño y lo propio, esto es de la otredad. Tan cierto es que la mirada es prefigurada a través de las normas culturales, dirigiéndola y determinando así la descripción, tan cierto es también que estas normas, a través del contacto y la percepción del otro y del intento de describirlo, tambalean y oscilan. Precisamente en esta tensión entre la percepción de lo inconcebible y absolutamente nuevo y desconocido (la belleza deslumbrante de Tenochtitlán, ciudad única en el mundo, y la ritualidad divina y señorial de Moctezuma), lo atroz (los sacrificios de seres humanos) y su representación en formas, géneros, procedimientos familiares tanto en la literatura como en los actos rituales, en la pintura o arquitectura nace lo que vengo llamando hibridación como un resultado de un proceso translatológico independiente de las ideologías y propósitos civilizadores. Esta es precisamente la intención principal de mi trabajo y de mis futuras investigaciones, con lo cual quiero también demostrar que nosotros académicos, también como los españoles del siglo XVI en su intento de aprehender lo extraño, operamos con prejuicios y categorías rígidas y prefiguradas en vez de mostrar cómo los españoles litigaban con la otredad.

En este contexto me parecen de principal importancia las observaciones de Rincón y Elliot (a este último retornaré en extenso más adelante) en cuanto abren nuevos caminos, por ejemplo, cuando Rincón (1990: 230), en su lectura de Relación de Yucatán de Diego de Landa, constata hibridación a través de la apropiación y translación de "formas externas de instituciones in- 
dígenas", tales como el "sistema de tributo", "estructuras de poder", "métodos colectivos de trabajo" o "ceremonias religiosas de iniciación" (Rincón 1990: 230), a pesar de que Landa, ciego de rabia y desprecio, hace quemar toda la biblioteca de los mayas. También Rincón apunta en este proceso a una oscilación entre destrucción y apropiación:

La sistemática destrucción de la cultura indígena que se puede ver en el proceder de los conquistadores y misionarios en el campo central de la religión, presupone por otra parte el esfuerzo de servirse de elementos indígenas, formas e instituciones en servicio de sus propios propósitos (Rincón 1990: 230; mi traducción).

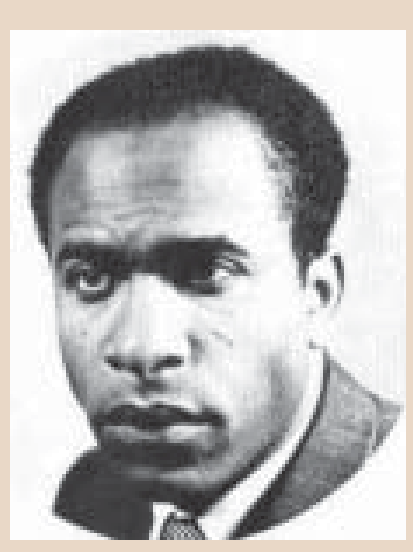

F. Fanon

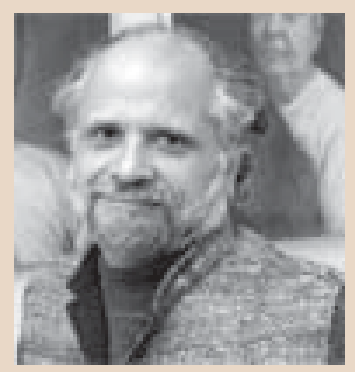

Homi Bhabha

Precisamente en esta cita podemos constatar pars pro toto que, aun cuando se trate de un acto de apropiación, o canibalismo cultural, de las prácticas culturales para doblegar y apaciguar a los indios y así con poca resistencia de su parte fomentar e introducir el Evangelio exitosamente, el resultado que se obtiene es una hibridación a través de la translación por medio de analogía, comparación y similitud que se encuentra más allá de la intención o voluntad originaria de los conquistadores o misioneros, estableciendo así un estado de otredad. Este es un primer y breve ejemplo al respecto.

Mi posición se basa en algunas premisas fundamentales. Quisiera recordar que si no fueron postuladas primero por Bhabha, sino por Frantz Fanon en Peau noire masques blancs (1952), por Memmi en el mencionado libro y también en los Écrits por Lacan (1966), Homi Bhabha (1994), en todo caso, las reformula con gran claridad y productividad.

Debería entre tanto existir un consenso, creo al menos, en que toda comunicación representa una doble anegación de una enunciación de un sujeto en cuanto en la metáfora del espejo de Lacan y su concepto de la castración -como así también en la categoría de 'mímicra' que Bhabha toma de Lacan-, el sujeto se experimenta como otro y su lengua como la de un tercero, como un infinito deslizamiento (glissement), como una continua metonimia. Por otra parte es válido decir que todo enunciado se relaciona en un acto de comunicación con otros enunciados y que semejantes enunciados desembocan en un espacio entre-medio, es decir, se proliferan autónomamente y establecen una infinidad de relaciones.

Este hecho tiene serias consecuencias para los conceptos de cultura, de espacio cultural, de identidad y para la percepción y descripción de la otredad, ya que en este lugar podemos constatar que encuentros de culturas -cuan hegemónicos, jerárquicos y asimétricos sean- nunca se producen en forma estática y unilateral. Por esto diría que la hibridación y su proceso de translación son una evidencia y que negarlos es prácticamente imposible.

El acto de enunciación cultural está acuñado por la diferencia que radica en el acto de enunciación mismo, de tal modo que en todo acto de comuni- 
cación actúan diferentes aspectos que son fundamentales para la codificación de la significación y para la diseminación. Por esto, un enunciado y sus enunciados no son nunca puros o transparentes sino que conllevan una disjunción antropológica lingüística básica entre sujeto y enunciación.

\subsection{Stephen GReEnblatt o la incapacidad de los españoles DE REGISTRAR LA OTREDAD}

Dentro de la discusión de la evaluación del acto de la Conquista, Greenblatt argumenta -en parte siguiendo a Lacan y basándose en su propio término de "mimetic circulation" (Greenblatt 2001: 119) o de "some degree of mimetic circulation" (Greenblatt 2001:121)-particularmente con respecto a las prácticas de representación dentro de relaciones claramente jerarquizadas y unilaterales de la relación entre conquistadores y conquistados. Se trata de una permanente circulación de conocimiento, de formas de vida, de rituales religiosos, que, según Greenblatt, a los españoles se les produce un 'bloqueo' necesario, al parecer frente a la imposibilidad de digerir lo observado y experimentado para el mantenimiento de la propia identidad cultural. En todo caso hay que considerar que un bloqueo no puede ser absoluto ya que la cultura es permeable y solamente a través de un dispositivo normativo excluyente puede permanecer estable ${ }^{1}$ :

Cultures are inherently unstable, mediatory modes of fashioning experience. Only as a result of the social imposition of an imaginary order of exclusion -through the operation of what in the discussion that follows I will call 'blockage' - can culture be invoked as a stable entity within which there are characteristic representations that are ordered, exports, accommodated. Such blockage occurs constantly -an infinite, unrestricted, undifferentiated circulation would lead to the collapse of identity altogether- but is never absolute. The rhetoric of absolute blockage is everywhere in the discourse of early modern Europe, but the reality is more porous, more open, more unsettled than it first appears. Any element in the structure of a culture is potentially up for grabs. Any idea, however orthodox, can be challenged. Any representation can be circulated. And it is the character of this circulation -secret or open, rapid or sluggish, violently imposed or friendly embraced, constraint by guilt and anxiety or experienced as pleasure- that regulates the accommodation, assimilation, and representation of the culture of the other.

\footnotetext{
${ }^{1}$ Semejante 'bloqueo' o la incapacidad de percibir al otro (o de aceptarlo, ya que de eso se trata al fin en el caso de Greenblatt como veremos) no es un fenómeno nuevo ni único ni tampoco fue tratado inauguralmente por Greenblatt, sino que anteriormente fue tratado por Elliot (1970: 14) refiriéndose a la recepción y consecuencias de la Conquista en el viejo mundo (vid. más abajo).
} 
This representation is never quite synonymous with direct possession of social reality which is always mobile and exclusive, though the discourse of travel is saturated with the glittering promise of such possession and record extraordinary steps taken to secure it (Greenblatt 1991: 121).

Esta cita demuestra que -como veníamos argumentando- el acto de comunicación, de translación y de interpretación no es nunca unilateral entre un yo y un tú que en el acto de comunicación o en el intercambio de miradas abandonan sus respectivos territorios en forma involuntaria y comienzan a construir un hors territoire (Derrida: Lemonolinguisme del'autre). De esta situación de tensión resulta la ambivalencia de la enunciación y de la interpretación que Bhabha formula de la forma siguiente:

It is only when we understand that all cultural statements and systems are constructed in this contradictory and ambivalent space of enunciation, that we begin to understand why hierarchical claims to the inherent originality or "purity" of cultures are untenable, even before we resort to empirical historical instances that demonstrate their hybridity (Bhabha 1995: 208),

que subraya la indeterminación de la localización de la enunciación y su descentración. Esto nos pone en claro que símbolos y significación cultural no constituyen una unidad determinante y no están fijados a priori, muy por el contrario, vemos incluso que signos que nos son familiares son nuevamente reapropiados y recodificados.

La deslocalización se produce como resultado de un funcionamiento metonímico cada vez que la mirada y las estrategias de percepciones son apareadas con la imaginación, un proceso translatológico e híbrido en sí. Greenblatt (1991: 130) menciona de la "autonomía” de Bernal Díaz como narrador, su ironía y la crítica contra Cortés respecto de acciones atroces que luego son justificadas por éste con argumentos religiosos. Sin embargo, Greenblatt le niega a su relato un estado híbrido, ya que -según él- el efecto de la ironía está limitado a raíz del 'bloqueo'. Seguramente, el discurso de Bernal Díaz tiene sus límites, pero en la oscilación entre estrategias de legitimación, crítica y efecto irónico se genera la hibridez. A pesar de esa "strategy of mimetic blockage or exclusion” (Greenblatt 1991: 130) Bernal Díaz logra describir lo observado y vivido desde una perspectiva de abajo, marginal e interna y llena de rupturas y cambios que son fundamentales de considerar para valorar su discurso, ya que éstos son también mecanismos de donde resulta la ambivalencia, un fenómeno que nos es muy conocido en la teoría y práctica de la narratología. Bernal Díaz reconoce y describe las similitudes entre rituales religiosos aztecas y españoles, lo cual Greenblatt le niega. Este 
se pregunta cómo Bernal Díaz logra producir una insalvable diferencia entre ambos sistemas -negando de esta forma las evidentes similitudes y equivalencias (Greenblatt 1991: 199-200)- y cómo logra Bernal Díaz ignorar las ocultas y subterráneas similitudes. Naturalmente que en este caso la táctica juega un papel central. Reconocer a los aztecas significaría aceptarlos como iguales, lo cual contradiría los fines de la Conquista, ¡pero ésa no es la mentalidad de la época, sino una posición actual!

Sin embargo, los muchísimos rituales religiosos se mezclan con prácticas cristianas y aztecas cambiando la perspectiva, más de lo que Greenblatt supone. De hecho la comparación es parte de la permeabilización y de la relación de ambos sistemas culturales.

Algunas valorizaciones de Greenblatt son algo generales y resulta difícil seguirlas; por ejemplo, cuando él reprocha a Bernal Díaz el criticar la atrocidad de las prácticas religiosas de los aztecas sin mencionar las atrocidades cometidas por los españoles contra los judíos y musulmanes. La comparación es altamente problemática, ya que existe una diferencia fundamental entre la despiadada persecución y matanza de los judíos a finales de los siglos XIV y XV y de la persecución de los conversos en los siglos XVI y XVII y las inmolaciones de seres humanos y el canibalismo ritual de los aztecas. Estos últimos le sacaba el corazón a las víctimas aún vivas. Fuera de eso la tortura no era solamente un problema de los españoles. Montaigne en su ensayo "Des Cannibales" procede en forma muy diferenciada, hace pasar lista a las atrocidades de los europeos contra sus enemigos y las califica de peores que el canibalismo ritual donde al menos -así Montaigne- las personas estaban muertas.

El problema en la argumentación de Greenblatt es, por una parte, que para él la construcción y la comprensión del otro y, por otra la aceptación del otro es un mismo acto. Entendido así sería esta equivalencia, en el mejor de los casos, parte de una conciencia postcolonial en el sentido de la construcción de un tercer espacio donde los actores negocian conscientemente sus identidades construyendo un espacio híbrido en la segunda mitad del siglo XX. A partir de los siglos XV y XVI en adelante, construir al otro quiere decir solamente registrar al otro a través de la comparación, analogía y similitud en un acto de translación. Naturalmente que el acto de 'registrar' tiene sus límites, ya que siempre se encuentra de por medio el propio sistema normativo; otro no está disponible (lo cual también es válido para las estrategias de la hibridez del siglo XX y XXI). Además la lengua fracasa frente a la novedad y diversidad del mundo observado que tiene que ser codificado.

Greenblatt ve una de las razones del aparente 'bloqueo' de Bernal Díaz, como representante de los españoles frente al otro y su exclusión, en la inmolación de víctimas humanas y en el canibalismo ritual, que son "perversiones" a las cuales se le suman un buen número de otras como alcoholismo, abusos y perversiones sexuales o sodomía -que por lo demás también

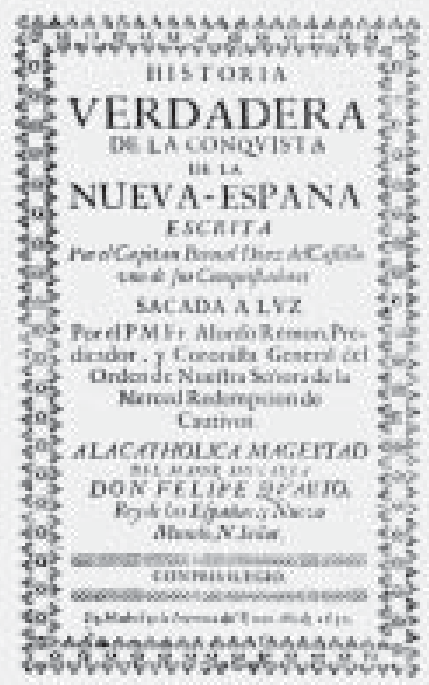


existían en el canon de perversiones de Europa desde la Antigüedad grecolatina-, la similitud entre los rituales cristianos de inmolación (Cristo crucificado en vivo, el consumo de carne y la bebida de la sangre de Cristo en la misa). Pero la comparación de Greenblatt se encuentra también en este caso fuera de lugar y no es ésta la razón del supuesto 'bloqueo' de los españoles para construir o percibir al otro, sino que la inmolación de seres humanos y el canibalismo ritual constituyen un barrera insalvable/intraducible entre ambas culturas.

Greenblatt critica además el recurso a la comparación, analogía y similitud de Bernal cuando éste describe Tenochtitlán o el mercado de Tlatelolco poniéndolo por sobre famosas ciudades de la Antigüedad, de la Europa y España contemporáneas o cuando compara los edificios y artistas aztecas con los europeos. Todo esto es para Greenblatt una ficción en el contexto del género de lo maravilloso y de las novelas de caballerías ${ }^{2}$. Sin embargo, yo más bien argumentaría que estas comparaciones con lo deslumbrante es un topos típico de la Antigüedad para el reconocimiento de la grandeza del otro y no un acto de ceguera hegemónico. Precisamente el recurso a la similitud y a la analogía le permite a Bernal Díaz conectar lo extraño con lo propio y captar la otredad, de digerir la conmoción (shock) de lo extraño-maravillosohorroroso, como también indica Elliot. Y hay muchos ejemplos: Durán inicia la descripción de un proceso de hibridación constatando las admirables analogías entre los actos y prácticas religiosos de los aztecas y cristianos donde se perfila un "tercer espacio" (Cfr. Todorov 1982: 213; y vid más abajo). Este recurso, a mi modo de ver exitoso, es calificado por Greenblatt como un perfecto fracaso de Bernal Díaz -el primer narrador americano, como lo califica Carlos Fuentes (2002: 178)- y de su completa incapacidad de captar al otro:

The absolutely other cannot be conveyed at all, cannot perhaps be even perceived, but the romance can at least gesture toward this other, marked with the signs of fantasy, unreality, enchantment (Greenblatt 1991:133).

El supuesto fracaso no lo es verdaderamente, sino que tenemos el problema de traducir el horror que no se deja asimilar en las propias normas o tenemos que traducir la maravilla que la lengua y la experiencia no son capaces de abarcar. El problema es, en ambos casos, de translación y de visualización: cómo codificar y cómo transportar al lector no presente lo visto y experimentado (Cfr. Elliot 1970: 28-29, Todorov 1982: 212-213).

El rigorista dominicano Durán emplea los mismos métodos que Bernal

\footnotetext{
${ }^{2}$ Esta central tesis de Greenblatt proviene también de Elliot quien a su vez reprochaba a Bernal Díaz que éste "still looks at the conquest of Mexiko throug the haze of romances of chivalry" (1970: 20).
} 
Díaz. Queriendo captar los rituales y prácticas religiosas de los indígenas para así propagar en forma más eficaz el Evangelio (como también argumenta Sahagún) es invadido por la realidad de la otredad de los indígenas.

Greenblatt deja no sólo estos aspectos fuera de su argumentación, sino que tampoco considera estrategias impuestas por la censura de la corte y de la Inquisición y en este contexto la analogía, la comparación y la similitud eran formas, por una parte, de protección y, por otra, de hacer asimilable, "digerible" y aceptable lo descrito.

Otra razón del aparente bloqueo y de la exclusión del otro que según Greenblatt llevan a la destrucción de Tenochtitlán y la explican -a pesar de la admiración que los españoles le tienen a esa fascinante ciudad- es de tipo psicoanalítico: los españoles destruyen a raíz de un imperativo psicológico Tenochtitlán porque, como indescriptible maravilla, no la podían poseer. El estado absolutamente imaginario y por esto efímero de Tenochtitlán se les escapa de la aprehensión y en el terror de perder el objeto del deseo, lo destruyen para así no perderlo. Se trata pues de un acto pasional: "Only when it is violated, turned into a charnel house, can it be taken as a reality and appropriated" (Greenblatt 1991: 134)3. Los españoles no destruirían por razones de poder y de codicia, sino impulsados por un deseo monstruoso frente a una amante indomable que se les escurría constantemente. Impotencia y desesperación determinan la conducta de actores altamente esquizofrénicos, paranoicos, disturbados mentales, de delincuentes sexuales que reprimen una obsesión sexual aberrante que se descarga en una violación de tipo caníbal y que momentáneamente es satisfecha al devorar el objeto del deseo. En la destrucción-desaparición-engullimiento del otro se realiza la apropiación absoluta.

Una última razón del 'bloqueo' y exclusión es lo que Greenblatt denomina el "transcendent design" (1991: 134). Una vez que los españoles penetran en Tenochtitlán irrumpe una profunda desilusión al registrar en la capilla del templo mayor el tipo de rituales sangrientos de los aztecas que Bernal Díaz del Castillo considera más terribles que los mataderos en España y que, como habíamos apuntado más arriba, es descrito por Bernal Díaz del Castillo como algo aparentemente único, jamás visto hasta la fecha, lo cual Greenblatt critica como bloqueo, ya que Bernal Díaz ignora intencionalmente las semejanzas con los rituales cristianos, a pesar de su evidencia: "That his own religion centred on expiatory sacrifice and upon the symbolic eating and drinking of his god's body and blood" (1991: 134). También en este caso los españoles se comportan en forma esquizofrénica, que consiste en que quedan espantados al constatar las semejanzas de ambos ritos religiosos, es decir, que los aztecas llevan a cabo concretamente aquello que el rito

\footnotetext{
${ }^{3}$ También esta teoría de lo maravilloso y de la translación de lo inalcanzable recurriendo a John Mandeville y a Herodoto provienen de Elliot (1970: 31).
} 
cristiano realiza simbólicamente; esto impulsa a los españoles a eliminar a los aztecas para así deshacerse del horroroso espejo de sí mismo. Tenemos un acto de represión y sustitución -que también son dos estrategias translatológicas: tanto lo encubierto y lo articulado-:

That his own religion centred on expiatory sacrifice and upon the symbolic eating and drinking of his god's body and blood does not inhibit Bernal Díaz's horrified response to what his culture construed as the weirdly literal Aztec equivalents (Greenblatt 1991: 134).

Exactamente en esta semejanza radica el asombro, la repugnancia y la diferencia, que representa la puesta en acción de lo simbólico, pero la semejanza no es reprimida, sino que la crueldad y el horror son descritos con un lujo despiadado de detalles. Durán, por ejemplo, pone en evidencia los paralelos entre ambos sistemas religiosos, por ejemplo, en la construcción de la trinidad, como también lo hace el Inca Garcilaso en relación con el sistema religioso incas. Las tesis de Greenblatt provienen en su totalidad de Elliot y Todorov, pero las invierte en su aspecto negativo. Mientras que para Todorov las estrategias de analogía y comparación son pruebas de una hibridez no premeditada o métissage, el freudiano Greenblatt invierte el camino de la registración de la otredad en bloqueo. Precisamente el momento de consentir la otredad a través de la descripción y comparación, es el primer momento de superar un bloqueo total: el enunciado descriptor representa el momento del desprendimiento (Entäußerung) y este mecanismo es ignorado, y revertido por Greenblatt, al contrario de Todorov, quien opina:

Ce que nous voyons surtout est que Duran s'arrange pour découvrir des ressemblances là où les idolâtres qu'il pourfend en même temps n'avaient jamais osé les chercher : à l'en croire, on pourrait se contenter d'obéir à l'ancienne religion, à quelques modifications près, puisque c'est la même que la nouvelle! Duran appelait l'Inquisition et l'anathème sur ceux qui mélangeaient les deux rites, ou même pour ces autres, professionnels du culte chrétien, qui n'étaient pas assez sévères à l'égard des premiers; mais quel jugement aurait-on porté sur lui si on avait su que confession et baptême, Noël et Pâques, et même la Trinité, n'étaient à ses yeux en rien de différents des rites et de conceptions propres aux païens Aztèques? Ce qui lui paraissait l'infamie la plus grande -le syncrétisme religieux-, Duran l'avait dans son regard même... (Todorov 1982: 212).

Las siguientes aseveraciones y críticas a Bernal Díaz por parte de Greenblatt son difíciles de comprender y muy polémicas, sobre todo cuando sostiene:

But it is significant that in Bernal Díaz absolute difference is established at the site of the most intimate and uncanny parallel, the site where the 
secret sharing would under different circumstances have occurred: in the temple, where high altar, holy blood, and the mysterious signs of cross produce wonder and revulsion (Greenblatt 1991: 136).

Exactamente ése es el punto: bajo “otras circunstancias podría...”, ¿pero bajo cuáles? ¿Qué actitud y conciencia espera Greenblatt de los españoles y europeos de hace 500 años? ¿Por qué Greenblatt rehúsa distinguir entre el acto simbólico "caníbal" y de inmolación del cristianismo de aquel de los aztecas donde las paredes de la capilla están tapizadas de sangre corrompida y nueva, humeante, donde los papas se cubren con la piel aún caliente de las víctimas? Frente a este espectáculo Bernal Díaz no reacciona de ninguna manera con el 'bloqueo', como luego veremos con más atención. ¿Qué actitud persigue Greenblatt? Al parecer, la alternativa para él es describir este horror en forma neutral y aceptar la diferencia y compararla con las propias prácticas. La imposibilidad de aceptar semejante diferencia y de compararla con prácticas contemporáneas propias es algo que hasta hoy existe: por ejemplo, los "asesinatos de honor" realizados por mano de varones turcos cuando sus hijas o hermanas tienen relaciones sexuales con jóvenes de su edad (algo que sucede cada vez más frecuentemente en Alemania). Fuera de eso, Bernal Díaz era un simple soldado que al parecer casi no sabía ni escribir ni leer muy bien -hasta el punto de que circula la opinión de que su libro fue dictado-, y mucho menos fue un teórico postcolonial de la cultura del siglo XX o XXI.

La Conquista no fue para los españoles un simple juego de representaciones sino consistió en duros hechos, fue una misión que se trataba de vida o muerte. Por ello no es una sorpresa que frente a las vestimentas sangrientas de los papas, a los corazones colgados a granel, frente a la sangre escarchada y apestante era más que imposible traducir semejante horror en analogías y similitudes con el cristianismo. Más bien nuestra tarea es investigar en qué medida los españoles eran prisioneros de su situación cotidiana y en qué medida podían desarrollar al nivel de la representación discursiva una escenificación translatológica capaz de construir la otredad. Esto es simple de demostrar en un buen número de crónicas y escritos de diversa proveniencia, sin embargo, para ello debe tener lugar de una nueva aproximación a estos textos.

La pregunta que sólo en una dirección Greenblatt hace es ¿cómo pudo Cortés creer por un momento que era posible reemplazar la cultura de los aztecas en forma completa por otra?: "that his culture's symbols can simply replace the symbols of an entirely different culture?” (Greenblatt 1991: 137). La pregunta nos muestra la ideología subyacente que nos dice que Cortés como invasor no tenía ningún derecho a transformar el sistema. Por otra parte, es un error de Greenblatt sostener que la cultura azteca fuese completamente reemplazada. Más allá de lo que un conquistador crea o no crea, 
estaba fuera de su poder controlar la red de relaciones que se desarrolla en un acto de translación de semejante envergadura. Además, suponer otra alternativa nos revela un pensamiento iluminado y tolerante que se comienza a generar en el siglo XVIII, pero particularmente en la segunda mitad del siglo XX en Europa, lo que no quiere decir que un pensamiento hegemónico que dé la prioridad a la cultura propia haya dejado de existir; los acontecimientos en Irak y la política de los diversos gobiernos norteamericanos frente a Latinoamérica y en particular la política de la administración de Bush frente a Irak y al mundo árabe o también el último libro de Huntington, Who are we? -que se lee como la cara teórica de la política exterior del régimen norteamericano-, demuestran que las expectaciones de Greenblatt representan más bien una idealizada forma de las teorías postcoloniales.

No tenemos que hacer gran esfuerzo para imaginarnos cómo el mundo actual reaccionaría frente al canibalismo y la tortura. Por otra parte, es sorprendente con qué impunidad la administración norteamericana se vale de la tortura sistemáticamente organizada en el nivel empresarial para alcanzar sus fines en Irak ignorando sus propias leyes. Es sorprendente cómo reacciona la administración norteamericana frente al escándalo de la tortura en Guantánamo, Afganistán y en Abu Ghraib. Rumsfeld acepta que "posiblemente se ha actuado contra la Convención de Ginebra", y a la pregunta si es un acto inhumano el obligar a prisioneros a pasar horas inmóviles sobre un cajón, con una capucha sobre la cabeza, con un cable de electricidad alrededor del cuello, que en el caso de caerse lo electrocuta, responde Wolfowitz balbuceando, luego de haberse negado varias veces a responder la pregunta: "sí, él piensa que podría ser inhumano". Los videos y grabaciones muestran un placer en la liquidación de seres humanos considerados inferiores, algo que es casi imposible comprender. Estos horrores son cometidos en el siglo XXI por una de las más ejemplares democracias que sólo quería aportar algo bueno a Irak, como en décadas anteriores en Vietnam.

La comparación es necesaria, no para trocar un mal por otro o para legitimar un horror frente a otro, lo cual sería un gran error, sino para hacer consciente que Greenblatt exige implícitamente con su crítica a los españoles del siglo XV y XVI la conciencia ilustrada y postcolonial de un etnógrafo y no de monjes y conquistadores, de un etnógrafo que tiene la distancia frente al objeto analizado, una distancia que al mismo Greenblatt parece habérsele extraviado. En este contexto y frente a lo expuesto nos parece, al menos históricamente, problemático el empleo de términos tales como "crimen" o "genocidio" (como también los utiliza Todorov) que han sido empleados en contextos históricos determinados como el nazi, en la Modernidad. ¿Cómo deberíamos calificar las cruzadas, que hasta la fecha no han sido olvidadas en el mundo musulmán y que hasta la fecha son alabadas en el mundo cristiano, y son parte de la mitología cristiano-occidental? 


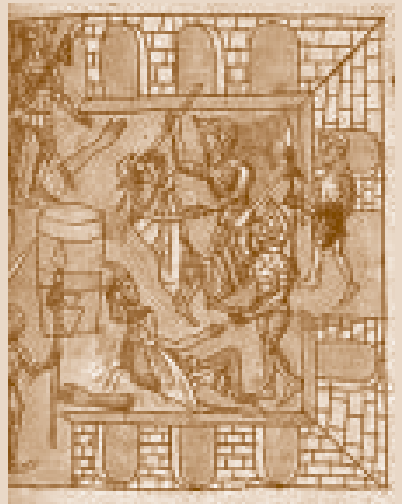

Greenblatt comprende muy bien el uso de la elipse con respecto a hechos bien conocidos que llevaron a la destrucción de Tenochtitlán. Por ejemplo, la creciente agresión contra los invasores por parte de la nobleza azteca en desacuerdo con el vacilante Moctezuma y la pérdidad de su autoridad; la prisión de Moctezuma, el lugar geoestratégico incierto de Tenochtitlán que representaba una desventaja logística para los españoles, ya que se les escapa del control, los hechos de la "Noche Triste", etc. Las tesis de Greenblatt nos parecen en un primer momento altamente seductoras a raíz de su originalidad, pero como ya hemos indicado varias veces, éstas provienen de Elliot y en parte de Todorov y son el resultado de una lectura psicoanalítica de la Conquista de México basada en el sistema de la represión y deseo, con lo cual se abren las puertas a una especulación deliberada:

For the blockage that constitutes a recognition of distance excites a desire to cross the threshold, break through the barrier, enter the space of the alien. The greatest scene of wonder in the Conquest of New Spain takes place on the straight and level causeway leading into the city, the immobilized moment before the Spanish embark on the path of penetration (Greenblatt 1991: 135).

Incluso si Greenblatt tuviese razón, sus tesis son tan reduccionistas que obstruyen el camino que él mismo había abierto con los términos "de la circulación mimética" (Greenblatt 1991:119) o el "resto de circulación mimética" (1991:121) para analizar las prácticas representacionales de los españoles. A pesar de esto, queremos rescatar en forma productiva aquello que Greenblatt deja de lado, es decir, cómo funciona esta "circulación mimética" o sus restos, se concretiza en los textos de los cronistas produciendo hibridez: aquello que menciona Elliot -retomado en extenso por Greenblattque Herodoto en su historia es capaz de describir la otredad de los Skythen (pueblo nómada y bárbaro en la periferia de los límites de la Grecia de ese entonces) en cuanto establece analogías con su propia cultura. Esto es exactamente lo mismo que hace Bernal Díaz con la $\mathrm{H}$ istoria verdadera dela Conquista dela Nueva España. Para Greenblatt Bernal Díaz del Castillo "understandably does not indulge in that sense o mimetic circulation, secret-sharing with the alien, that characterized Herodotus' history and Mandeville's travelogue" (1991: 136).

No es mi interés primordial demostrar la generación de hibridez donde no hay, pero en el encuentro y en la confrontación de culturas probar que no se genera un proceso de hibridación es prácticamente imposible. La hibridación es un resultado de translación dinámico de fenómenos históricos, políticos y culturales que se escapa al control normativo de sus actores.

Mi posición se encuentra formulada en una primera instancia por Todorov (1982: 216) con respecto a Durán: 
[...] toujours est-il que la rencontre dont il devient le lieu, entre civilisation indienne et civilisation européenne, fait de lui l'exemple le plus accompli du métis culturel au seizième siècle.

La rencontre de ces deux civilisations si différentes et la nécessité de vivre ensemble ne peut qu'introduire la disparité au cœur même de chacun sujet, qu'il soit Espagnol ou Aztèque,

constatando la evidencia que

[...] les Espagnols eux non plus ne peuvent sortir intacts de cette rencontre, et Duran, sans le savoir, dessine de cette manière ce qui est aussi son propre portrait, ou plutôt, écrit l'allégorie de son destin (Durán 1984: 216-217).

Muy por el contrario de Greenblatt, quien al parecer hace un aporte más a la leyenda negra donde los malos y los buenos están ya desde un comienzo bien establecidos:

The movement here must pass through identification to complete estrangement: for a moment you see yourself confounded with the other, but then you make the other become an alien object, a thing, that you can destroy or incorporate will (Greenblatt 1991: 135).

La posición preconcebida de Greenblatt se ve claramente cuando éste reprocha actitudes típicas de una conquista que es siempre, en todas las épocas, un acto violento, esclavizante, pero de donde nace algo nuevo. Algo simple nos resulta la crítica a la que Greenblatt somete a Cortés. Este y sus soldados son considerados como teules por los aztecas, lo que Cortés y sus hombres rechazan, y que sin embargo emplean como táctica para sacarle partido:

But out this momentary identification of self and other would come both absolute and difference and absolute possession: the Spanish would destroy the Teules and would break through the walls into the secret treasure chamber (Greenblatt 1991: 135).

El problema es que Greenblatt espera un comportamiento que se encuentra más allá de los parámetros de la realidad.

Un problema más representa la difusa descripción que Greenblatt hace del tiempo que toma el transcurso de los hechos. Nos da la impresión de que Cortés, en una sola acción, entra a Tenochtitlán, destruye los dioses, roba el oro y mata a los aztecas, quedando oculto que han pasado días y semanas en los que la situación se va agudizando, como lo describe Bernal Díaz del Castillo detalladamente. Esta reducción de la duración le permite a Greenblatt dar una visión fanática y sanguinaria de los españoles: "fanatically

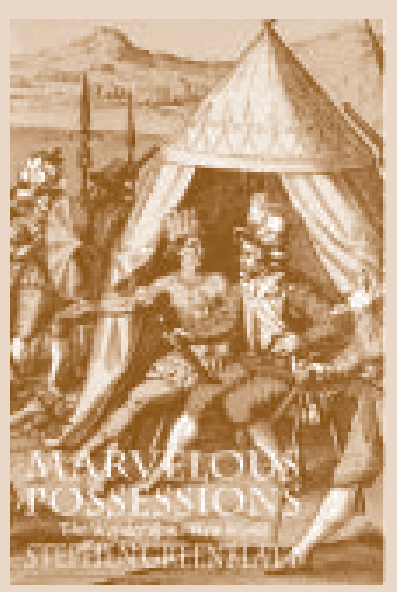


(6)

(a) 2 sous

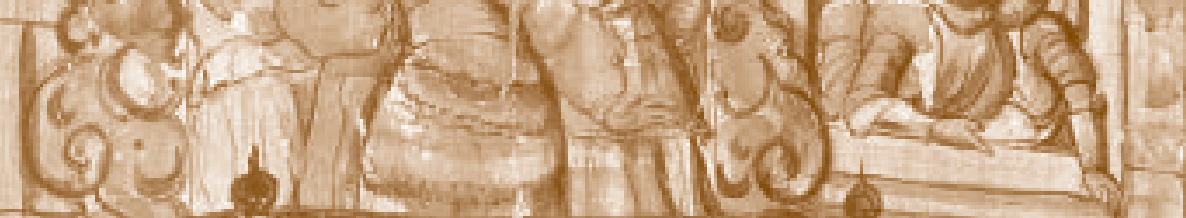

get $($ W

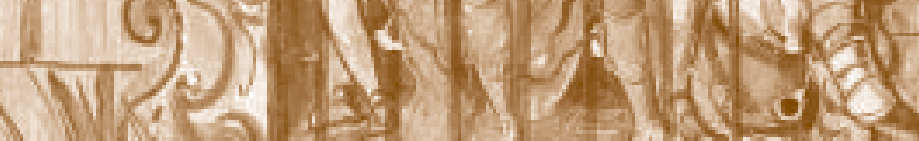

cras 19 and

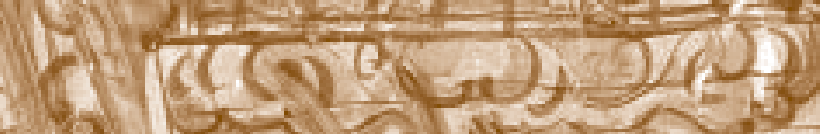

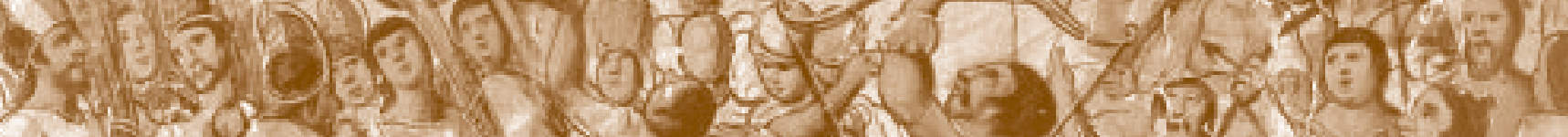
M

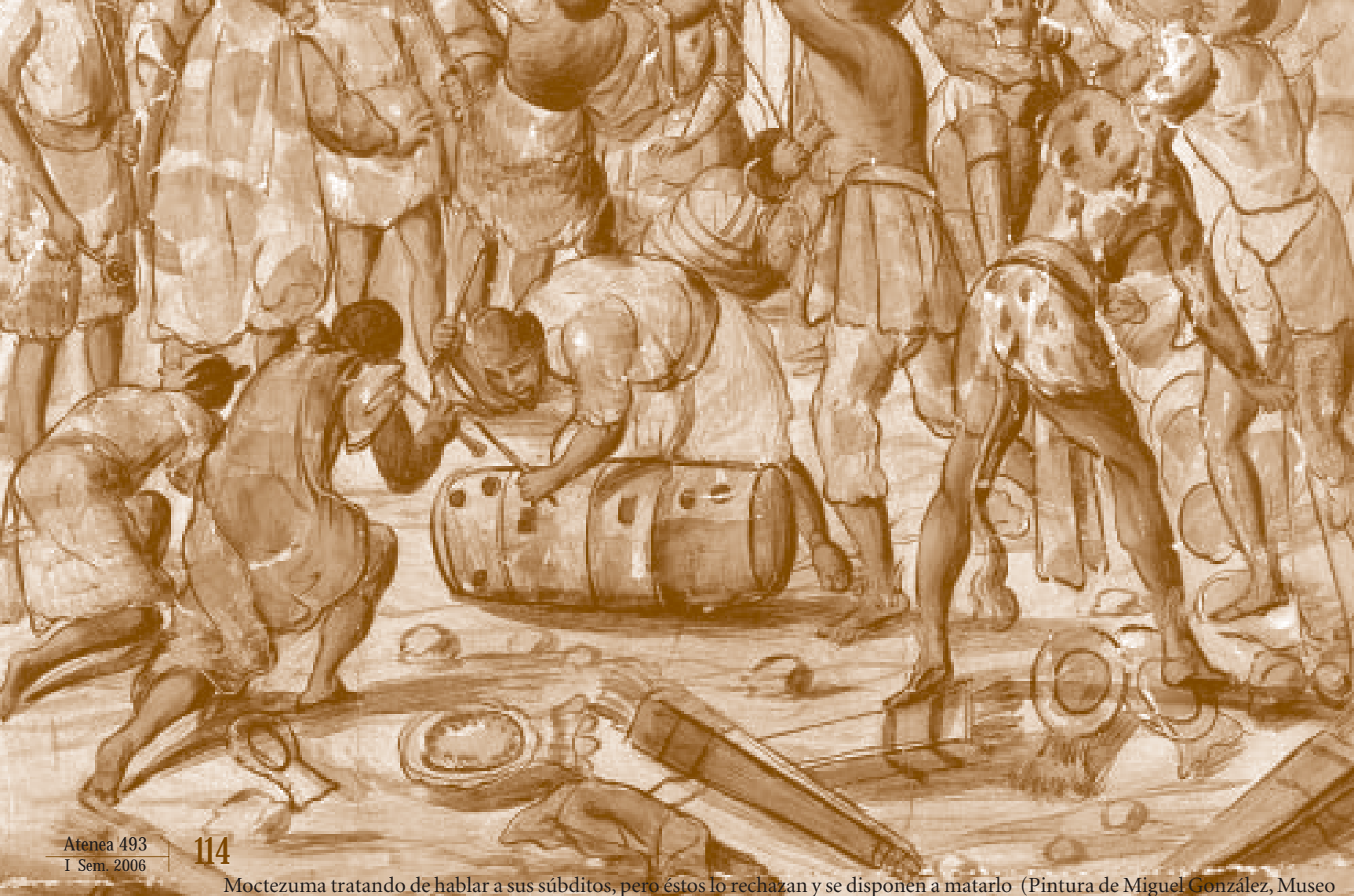
de América, Madrid). $(24=0)=08$ 
dedicated to swallowing the whole vast land mass and all of its peoples" (Greenblatt 1991: 136). Lógicamente, la Conquista de México y de Latinoamérica es para Greenblatt "the greatest experiment in political, economic, and cultural canibalism in the history of the Western World" (1991:136).

Por otra parte, Greenblatt (1991: 136-139) admite la precaria situación en que se encontraban los españoles: "Given who they were and where they found themselves, what else could they have felt?" (1991: 136), a lo cual Elliot también apunta constantemente. Por una parte, el canibalismo de los aztecas era un hecho y los españoles lo tenían como una amenaza constante, de tal modo que "a more detached, as it were anthropological, appreciation of the practice" (Greenblatt 1991: 136) no era posible. Por otra parte, propagar el acercamiento a las prácticas o a la mezcla de las prácticas religiosas de ambas culturas provocaba un conflicto con la iglesia y la inquisición, institución que con Torquemada estaba muy activa desde 1484. Un famoso ejemplo de los peligros que se corrían al entrar muy en detalle en la descripción de la cultura azteca lo representa Sahagún, a quien le confiscaron los libros, le hicieron un proceso y le quemaron la biblioteca. Por milagro se salvó el texto que hoy se llama código florentino.

Greenblatt desperdicia la posibilidad de iluminar la diversidad y complejidad de la Conquista a través de su interpretación unilateral, aportando así argumentos que tienen una perspectiva hegemónica de Latinoamérica y que ven en ella una cartografía de experimentación y proyección europea. De esta forma Latinoamérica le sirve a Europa para la definición de su propia identidad. Con ello se califica a todos los europeos como incapaces de aprehender la otredad. Simultáneamente, la argumentación de Greenblatt se presta para un tipo de debate fundamental esencialista que reclama pequeñas comunidades autóctonas y una identidad precolombina que desde 1492 no existe más.

En este contexto, Octavio Paz y Carlos Fuentes tienen una posición muy diferente a lo que fue la Conquista y lo que puede ser o es Latinoamérica hoy: ambos aceptan ese conflicto cultural como parte de la identidad latinoamericana. Paz, en su ensayo "Los hijos de la Malinche" de 1950 (Paz 1950/31973: 78), es un verdadero pionero con una mirada postcolonial e híbrida hacia el acontecimiento del Descubrimiento y de la Conquista. El "problema del origen" radica, según Paz, en la negación de la hibridez y agrega que los mexicanos no quieren ni provenir de los españoles ni de los indígenas, estas posiciones son más bien teorías de "unos cuantos extravagantes -que ni siquiera son blancos-" o de "criollos y mestizos maniáticos, sin que jamás los indios le hayan prestado atención" (Paz 1950/31973: 78).

Las tesis de Greenblatt representan un retraso frente a la discusión actual y quedan detrás de las renovadoras perspectivas de Paz, Elliot y Todorov, ya que no admiten que la conquista y destrucción de Tenochtitlán -el 13 de agosto de 1521- hayan significado una hora cero tanto para los españoles

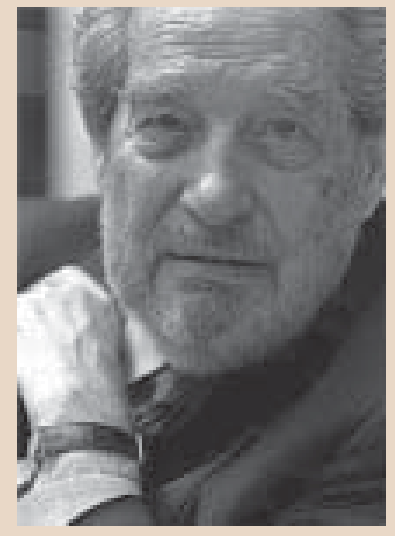

O. Paz

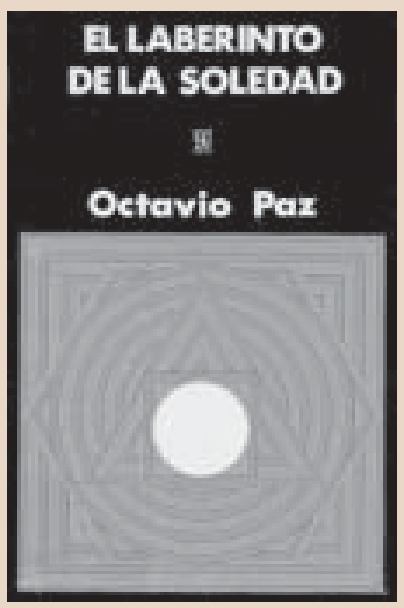


como para los aztecas. De allí la importancia que adquieren las observaciones de Paz cuando sostiene que el mexicano "no se afirma en tanto que mestizo, sino como abstracción: es un hombre. Se vuelve hijo de la nada. El empieza en sí mismo" (Paz 1950/31973: 79). Ese "en sí mismo" y la incorporación de la figura de la Malinche significan el punto de partida de una identidad y cultura híbrida en Latinoamérica ${ }^{4}$. De ese "en sí mismo" a la peyorativa evaluación que Greenblatt le da al proceso de hibridación volcado en los términos de "renaming, transformation, and appropriation" (Greenblatt 1991:135) o de la "articulation of radical differences" arranca precisamente la hibridez; en ese momento en el que Bernal Díaz construye la absoluta diferencia en la observación de los sacrificios en el templo es de donde se desprende la pregunta, ¿qué aporta la descripción de las diferencias absolutas traducida en similitud?

Y a pesar de la crítica hecha a Greenblatt hay momentos reconciliadores y fascinantes en su trabajo, por ejemplo, cuando éste trata de definir 'diferencia' en el sentido de 'diferancia' al hablar de "violent substitution" (1991: 138), o cuando los españoles en la isla de Cozumel al comienzo de su viaje observan con admiración una especie de misa que los indígenas celebran y luego éstos a su vez ven la misa cristiana de los conquistadores. Estos traspasos no son en absoluto simétricos, sino resultado de un proceso de translación sin el cual no serían posibles.

Realmente revolucionaria e innovadora para mis propias reflexiones es la mención de la idea de la "hermandad" por Greenblatt que realmente es la construcción de un mito, aun cuando Greenblatt saque al fin conclusiones negativas. Sobre esta base tratan Cortés y los españoles de convencer a los indígenas y a Moctezuma de abandonar sus ídolos según la fórmula de un "nostrum" común: "todos provenimos de Adán y Eva". Greenblatt (1991: 138) valora esta estrategia como "cínica e hipócrita", a pesar de que el solo hecho de considerar como hermanos a seres que adoraban dioses sanguinarios, que inmolaban seres humanos y cometían actos de canibalismo ritual era ya, aunque desde una perspectiva hegemónica, un acto osado:

[...] should not lead us simply to discard the myth of brotherhood, for the oscillation between brother and other under the sign of wonder is one of the principal tactics in Cortés's strategy of conquest and the principal representational device in Bernal Díaz's account of the peoples of Mexico (Greenblatt 1991: 138).

\footnotetext{
${ }^{4}$ Ya desde Gyurko (1977); Castellanos (1975/1987); Corpi (1978) y Alarcón (1983/1989) se viene generando una nueva interpretación de la Malinche que luego recibe un impulso fulminante con Todorov (1982). Esta trayectoria la continúa Margo Glantz (1994) y alcanza un punto de culminación con los trabajos de Wurm (1996) y Drörscher/Rincón (2001).
} 
Greenblatt admite que los españoles necesitaban encontrar un punto de conjunción "to be some point of contact for understanding to occur, some basis for communication and negotiation" (1991: 139) -aun cuando fuese "to facilitate the improvisational manipulation of the other" (1991:139), lo cual "cannot completely dispense with mimetic circulation, a sense of the underlying strategic intersection of representational forms". Mas, esta circulación mimética con resultados de superposiciones se neutraliza luego con el "bloqueo".

Paradoja, figuras oximorónicas, oscilación, pasajes, rupturas, muerte, reconocimiento, destrucción y lamento, nostalgia y deseo como figuras de la translación forman la estrategia de la hibridez, lo cual equivale a nuestro concepto de hibridez en el sentido de "otra forma de acercarse a la razón y a la historia, como una lógica de la 'suplementariedad', del 'pliegue,' 'repliegue' ('reploiement'), 'arruga' ('pli'), 'injerto' ('greffe'), el rodar de unidades culturales que no se dejan reducir ni a un origen cultural o étnico único -se trata de unidades que se resisten a ser asimiladas por estructuras superiores-, ni a una diversificación sin identidad" (A. de Toro 2002: 36-37).

Las tesis de Greenblatt -como en gran parte de aquellas de la investigación internacional- se quedan atrapadas dentro de un metadiscurso o pensamiento dicotómico en una perspectiva normativa eurocentrista de la Conquista.

Además, Greenblatt casi no presta atención a la fundamental figura del intérprete, un factor esencial del acto de comunicación porque tiene el poder de la translación, como lo plantea Carlos Fuentes en las palabras de Jerónimo de Aguilar:

El enigma de la debilidad de Moctezuma ante los españoles sólo lo puedo entender mediante la explicación de las palabras. Llamado el Tlatoani o Señor de la Gran Voz, Moctezuma estaba perdiendo poco a poco el dominio sobre las palabras, más que sobre los hombres. Fue ésta, creo yo, la novedad que lo desconcertó, y doña Marina acababa de demostrarle, argumentando con él cara a cara, que las palabras del Rey ya no eran soberanas (Fuentes 1993/ ${ }^{12} 1999: 26$ ).

[...]

Pues no eran joyas ni caricias lo que ahí se trocaba, sino palabras que podían darle más fuerza a Moctezuma que a todos los caballos y arcabuces de los españoles [...] (Fuentes 1993/121999: 27).

Las palabras, la traducción, representan el verdadero poder y son las que al fin construyen la realidad y la historia.

Cuando Bernal Díaz, en muchos de los episodios, narra parte de la traducción de la Malinche, la perspectiva no es sola y continuamente de Bernal Díaz, lo cual debe ser imprescindiblemente incluido en todo análisis narratológico (lo mismo es válido para la pluralidad de perspectivas en $\mathrm{H}$ istoria 


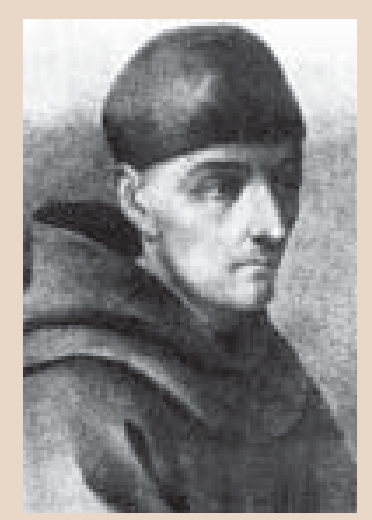

B. de Sahagún

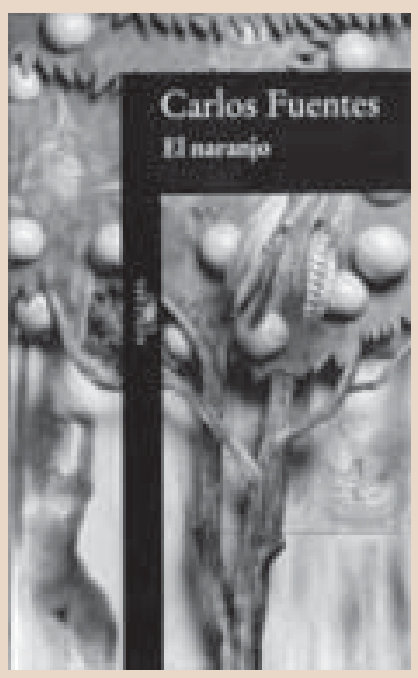

general de las cosas de Nueva España de Sahagún). Greenblatt, sólo muy al final de su trabajo y al margen, se ocupa de la Malinche, quien -como ya ha quedado establecido desde hace bastante tiempo, a más tardar después de Todorov (1982) - es una figura central de la Conquista que se mueve en varios mundos indígenas y entre el mundo indígena y el español, perteneciendo a ambos. Greenblatt considera a la Malinche como una especie de topografía sobre la cual se desarrolla la hibridez en cuanto afirma, coincidiendo con Adelaida Castillo y con la descripción que Bernal Díaz hace de la Malinche, que "[...] the site of the strategic symbolic oscillation between self and other is the body of this woman" (Greenblatt 1991: 143), lo cual ya Todorov (1982) como primero había formulado. Quisiéramos indicar que a pesar de toda la valorización negativa del proceso de Conquista, Greenblatt le concede al fin a la lengua un papel importante en el acto de la Conquista, como luego Carlos Fuentes lo escenifica un año más tarde en su libro El naranjo. Si la lengua pues ocupa un lugar primordial, si la Conquista es -según Greenblatt- "an emblem of the vast process of cultural translation" o la puesta en marcha de un gigantesco proceso translatológico a raíz de que los "European adventurers not only depended upon go-betweens, but were themselves go-betweens, servants of the great representational machine" (Greenblatt 1991: 145); si la Conquista desata una cascada de textos "that professes to deliver the New World to the Old" (1991:145), luego no podemos excluir de este proceso la hibridez porque todo acto de comunicación mimético implica un acto de translación y cada acto de translación implica hibridación. Translación significa necesariamente disponerse al otro:

Dona Marina is an extreme figure for the place of language at the centre of the technology with which Europeans in the late fifteenth and sixteenth centuries responded to the discovery of new lands. In her enigmatic power she serves not only as the supreme instance of the go-between in the New World but as an emblem of the vast process of cultural translation that the discovery initiated. For European adventurers not only depended upon go-betweens, but were themselves go-betweens, servants of the great representational machine. Journals, letters, memoranda, essays, questionnaires, eyewitness accounts, narrative histories, inventories, legal depositions, theological debates, royal proclamations, official reports, papal bulls, charters, chronicles, notarial records, broadsheets, utopian fantasies, pastoral eclogues, dramatic romances, epic poems - there is in the sixteenth century a flood of textual representation, along with a much smaller production of visual images, that professes to deliver the New World to the Old (Greenblatt 1991: 145).

Greenblatt, basándose en los ensayos de Montaigne, "Les Cannibales", reflexiona que en la Conquista existe, además de todas las asimetrías, una asimetría social donde los de abajo no alzan la voz ni toman la palabra, sino 
tan sólo las clases educadas. Montaigne reconoce este aspecto y por eso escribe su ensayo sobre la base de lo que su informante, un lacayo, le cuenta como testigo de lo sucedido en Brasil y, así, este informe adquiere un carácter "verdadero" y auténtico frente a los informes, crónicas y relaciones de los educados. Si aceptamos el topos romántico de "que todo lo bueno viene del pueblo" como Hugo en el siglo XIX lo formula, luego debemos conceder la misma "veracidad" y "autenticidad" a la historia de Bernal Díaz, un testigo, un hombre de humilde proveniencia, alguien que pertenecía a la gran masa de soldados y que -como hemos indicado- solamente con la ayuda de un tercero pudo contar su verdadera historia para obtener tanto él como sus semejantes el reconocimiento de sus méritos en la Conquista. Bernal Díaz cuenta esta historia no como un metadiscurso, sino como un testimonio personal y colectivo; nos abre las puertas a un sector sin voz, a una vivencia inmediata que luego ficcionaliza en el acto retórico de narrar.

Ensayemos un primer resumen: Greenblatt podría haber hecho un gran aporte basándose en su tesis del "resto de circulación mimética" o en la consideración de la oscilación de las contrucciones representacionales, si no hubiese avasallado su interpretación con una ideología prefigurada y altamente moralista: la leyenda negra. Ya antes de su análisis, los españoles constituyen los verdaderos monstruos de la Conquista que sólo tenían un fin: la eliminación total de los indios y la usurpación de sus bienes y riqueza. A pesar de que Greenblatt se mueve en el análisis tanto al nivel de los hechos como al de las representaciones, sólo se refiere obsesivamente a los hechos. Los resultados son previsibles: fuera de la destrucción quedan solamente representaciones vacías o aquellas que confirman los hechos, como también lo entiende Subirats.

Según Greenblatt, el famoso "bloqueo" psicológico intelectual de los españoles tiene dos razones: primero una razón consciente, no percibir al otro, ni pensar en reconocerlo, para poder así, más fácilmente, apoderarse de él. La segunda razón radica en la psicología profunda, es de orden psicoanalítico y opera al nivel de las perversiones psicológicas, de la represión del deseo y de la perversión: lo deseado y lo inconcebible/ increíble debe ser poseído a través de la subyugación y destrucción.

Greenblatt confunde niveles elementales o presupone implicaciones recíprocas donde éstas son imposibles, como Todorov (1982: 191) lo indica al tratar la alteridad. El hecho de que Las Casas aprecie a los indígenas no significa que los entienda y los acepte mejor o que no los quiera asimilar, esto es, eliminar la diferencia. El hecho de que Cortés "a su manera" conozca bien a los indios no significa que éste los acepte o se identifique con ellos. De allí que la distinción que Todorov (1992: 191) hace en tres niveles sea determinante: uno "axiológico" (la forma de las relaciones con el otro según los

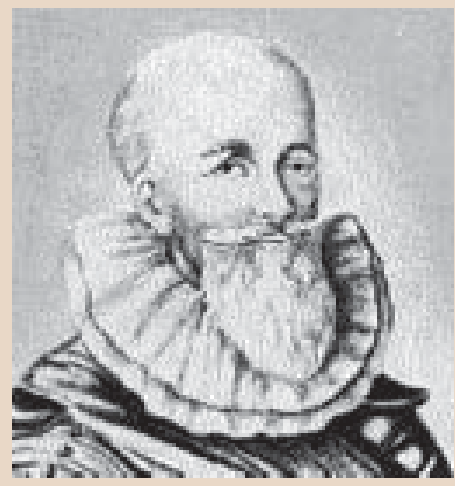

B. Díaz del Castillo 
criterios de igualdad o desigualdad); otro "praxseológico" (la forma de la relación con el otro según los criterios de identificación, asimilación, rechazo, reconocimiento o subyugación) y uno "epistemológico" (la forma de relación con el otro según los criterios de conocimiento o ignorancia frente al otro).

Finalmente, vemos el problema de la argumentación de Greenblatt en una ideología que reclama una conciencia de los conquistadores españoles que se le puede exigir a la sociedad actual, pero si ni ésta es capaz de cumplir con semejantes exigencias, hace 500 años sería imposible y, así, se sigue tejiendo la hidra de "leyenda negra". Greenblatt no aporta nada nuevo a los hechos; las partes más interesantes o provienen de Elliot o de Todorov o él mismo las desacredita con su juicio moralizante y de esta forma no abre nuevos caminos a la investigación.

\subsection{ELLIOT: 'OBSERVACIÓN,' 'DESCRIPCIÓN', 'TRANSLACIÓN', 'MEDIACIÓN'Y 'COMPRENDER' COMO ESTRATEGIAS DE LA CONSTRUCCIÓN DE LA OTREDAD}

El trabajo de Elliot, escrito veinte años antes que el de Greenblatt, es otra cosa muy distinta, sin embargo su alcance, que también parte de la prefigurada y normativa perspectiva de los españoles, es sacrificado a la indignación moral o al mecanismo de la represión que se expresa en una patología de la destrucción y de la muerte.

Más arriba hemos indicado cómo Elliot repetidamente apunta al difícil problema de la percepción y recepción de la Conquista y del encuentro con el otro, explicando cómo en el acto de descripción se produce una translación que cambia la perspectiva del español (Elliot 1970: 14-15) y cómo el Descubrimiento produce profundos cambios en todos los campos de la vida, del saber, de la política, economía, ética, teología, antropología, geografía, historia y filosofía (Elliot 1970: 6-7).

Hasta ahora, con el término de hibridez como resultado de un acto de translación, hemos tratado de demostrar que la Conquista, a pesar de la destrucción, no fue solamente unilateral y que por el contrario the conquest wrote back. El reescribir el Descubrimiento y la Conquista ofrece una aproximación innovadora. Para ello, Elliot parte de la posición básica que la Conquista no fue un camino en sentido único, sino que Europa y América forman una inseparable estructura que no puede ser interpretada separadamente ya que ambas se han influenciado mutuamente: "Properly, their histories should constitute a continuous interplay of two distinctive themes" (1970: 7). Según Elliot, hasta la fecha se han investigado la presencia y los efectos del viejo mundo en el nuevo, pero no al revés, cómo el viejo mundo 
cambió radicalmente con el descubrimiento del nuevo, una tarea que, por lo demás, aún prácticamente no se ha llevado a cabo y representa el más grande desafío. No solamente los conquistadores estaban deslumbrados por el mundo descubierto y no sabían certeramente dónde se encontraban, de tal forma que no podían ordenar lo observado por falta de referencias y analogías correspondientes. Mientras los europeos tenían alguna idea de Africa y Asia, sus conocimientos de América eran nulos. América en sus comienzos (Colón, Vespucio) era un "apéndice de Asia" como sabemos, y allí radica una de las explicaciones de por qué los españoles y europeos tuvieron grandes dificultades de entender el Nuevo Mundo, de comprender y asimilar la dimensión del fenómeno del Descubrimiento (Elliot 1970: 8) y de describir su diferencia, de la cual resulta un "desplazamiento temporal" (Elliot 1970: 8) que durará cien años antes de digerir el descubrimiento (Elliot 1970: 29).

Elliot reconoce, al contrario de Greenblatt, a pesar de "[t]he come down of the mental shutters" (1970: 14), que

[...] understanding is an intricate story of the interplay of prejudice, puzzlement and indifferences, where there is no clear linear progression, but rather a series of advances and retreats $[\ldots]$.

La consecuencia de este complejo, difícil y doloroso proceso de vaivén, de una oscilación permanente, es que una sociedad, cuando se toma la molestia de "comprender a otra", ésta "obligatoriamente se califica y se ve de una nueva y diferente forma" (Elliot 1970: 15). Elliot comparte asimismo la tesis de Winch (Phillips 1967: 30) de lo inevitable de la ampliación de las formas de vida y del abandonarse al otro en el encuentro de culturas:

Seriously to study another way of life is necessarily to seek to extend our own -not simply to bring the other way within the already existing boundaries of our own, because the point about the latter in their present form, is that they ex hypothesis exclude that other (Elliot 1970: 15).

La oscilación y el ocuparse del otro y de sí mismo se realiza bajo los ya mencionados momentos de la 'observación', 'descripción', 'translación/ mediación' y 'comprender'. A pesar de que Elliot (1970: 18-19) opine que los españoles por lo general no estaban empeñados en comprender al otro, sino en subyugarlo, y a pesar de que les reproche a los europeos describir desde su propia "tradición, experiencia y expectativa" (1970: 20) y a Bernal Díaz del Castillo describir la Conquista a través de la "haze of romances of chivarly" (1970: 20), al mismo tiempo Elliot admite que éste estaba empeñado -como Cortés- en traducir lo observado en la forma más exacta posible para "to bring the exotic into the range of the familiar by wrinting of Aztec temples 
as mosques, or by comparing the market-place of Tenochtitlán with that of Salamanca" (1970: 19), por medio de la comparación, similitud y analogía. "The human mind" -así Elliot- "has an inherent need to fall back on the familiar object and the standard image, in order to come to terms with the shock of the unfamiliar" (1970: 21), una experiencia, por lo demás, que todos conocemos muy bien. La fase de la comparación e incipiente translación es aquella en la cual los términos se tartamudean y balbucean, en la segunda fase se conecta lo desconocido con lo conocido, lo extraño con lo propio; ambos campos se relacionan, por medio de lo cual aparecen la diferencia, la similitud y las analogías. Este es el lugar del nacimiento de la hibridez, es decir, en la intersección de los pasajestranslatológicos a pesar del "bloqueo", de la limitación de la descripción prefigurada por una mirada normativa y de la carencia de una terminología y experiencia adecuadas.

Los cronistas tuvieron que lidiar con diversas dificultades: barreras lingüísticas, el fracaso de la propia lengua para registrar la otredad de un mundo enteramente nuevo y materialmente no codificado aún, la simultánea búsqueda de una mediación que permitiese además una posibilidad de entender para aquel que no estaba presente y no había tenido esa experiencia. Estos procesos translatológicos son exactamente los que desde un comienzo ponen la hibridación en marcha. Según Elliot (1970: 21), también la confrontación entre lo desconocido-horrorizante y lo conocido-familiar desenlaza un proceso de hibridación que genera cada vez más intensamente lo nuevo y lo otro. El recurso a la Antigüedad, el préstamo de monstruos y salvajes estereotípicos, no funciona en el Nuevo Mundo a raíz de la similitud entre españoles e indígenas; una experiencia que induce a los españoles a reflexionar sobre sus modelos. Además, el recurso a modelos familiares tiene un lado positivo que Greenblatt y Subirats desatienden completamente, pero no Elliot: estos modelos hacen posible la translación y la reducción a lo familiar; se trata de un procedimiento antropológico expandido e inherente a todas las culturas y, por ello, la analogía se puede incluso considerar como favorable en una primera etapa:

The reverence of late medieval Europeans for their Christian and classical traditions had salutary consequences for their approach to the New World, in that it enabled them to set it into some kind of perspective in relation to themselves, and to examine it with a measure of tolerant interest (Elliot 1970: 24-25).

Por otra parte, las proyecciones encubren las posibilidades de negociar la diferencia ya que los monjes y humanistas querían encontrar un paraíso que Colón les había descrito después de su primer viaje (Elliot 1970: 25).

El problema de percibir y aceptar la otredad en el Nuevo Mundo no radicaba tan sólo en las dificultades de su registro y en la descripción de lo 
maravilloso, como afirma Greenblatt, sino más bien en la relación permeable entre similitud y diferencia, ya que al querer describir primordialmente la diferencia, chocan con la similitud. Los indígenas no son ni monstruos ni salvajes como la Antigüedad conocía, tampoco son monstruos del gabinete de la mitología cristiana (cfr. Plinius, Friedman y Gewecke), sino que son mis semejantes, tienen un gran conocimiento de las maravillas y están altamente organizados. En estas circunstancias falla el repertorio de lo fantástico.

Aun cuando Elliot sostenga, con razón, que el deseo de saber y el utilitarismo, como así también el modelo clásico de la naturaleza de Plinius en su Naturalis Historia, poco ayudaron a registrar la otredad, o que el arte indígena, clasificado como arte bárbaro, no hubiese tenido ninguna influencia en el arte europeo, sino más bien sus objetos fueran parte de un parque exótico expuestos sin sistema como meros objetos y datos de colección de vitrina sin un aporte al conocimiento para calmar el ansia de posesión y de curiosidad, los europeos fueron también obligados, precisamente por el utilitarismo - a pesar de todo- "to widen their field of vision" -y aún más importante- "sometimes in spite of themselves [...] to organize and classify their findings within a coherent frame of thought" (Elliot 1970: 33). Así se agudiza la pregunta sobre la construcción de sentido de un comportamiento sin consideración de la otredad, de tal forma que la burocracia y la iglesia comienzan a captar la necesidad de que "the costums and tradition of the peoples entrusted to their charge" (Elliot 1970: 33). Recurriendo a Elliot quisiera dar dos ejemplos para lo expuesto. Uno proviene de la ocupación con la economía, el otro de la religión, lengua y cultura.

Como sabemos, Moctezuma exigía tributo de sus súbditos y de los pueblos subyugados o aliados. Esta práctica es reapropiada por los españoles para sus propios fines:

The visitas of royal officials to Indian localities therefore tended to turn into elaborate inquiries into native history, land tenure and inheritance laws; and the reports of the more intelligent and inquiring of these officials, like Alonso de Zorita in New Spain, were in effect exercises in applied anthropology, capable of yielding a vast amount of information about native customs and society (Elliot 1970: 33).

El segundo ejemplo lo tomamos del monje franciscano fray Bernardino de Sahagún, quien hasta 1669 termina con su obra magna Historia general delas cosas deN ueva España, y que se edita en una edición bilingüe en 1677, conocida bajo Codice Fiorentino, y del trabajo del monje dominicano fray Diego Durán con su Historia delas Indias deNueva España del año 1681. En ambos trabajos los monjes narran que quieren investigar la religión de los 


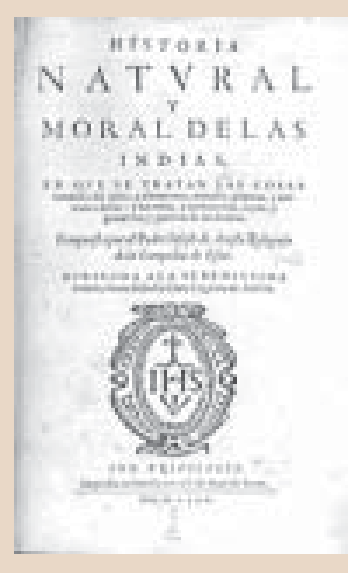

indígenas para entenderla mejor y así poder prohibir ciertos ritos incompatibles con sus normas e integrarlos al rito cristiano. Estos verdaderos etnógrafos, según Elliot, se sumergieron de tal forma en la cultura indígena que transgredieron las metas de la mera comprensión, de sus métodos y disciplinas (Elliot 1970: 33-34). No solamente aprendieron la lengua de los aztecas, sino que escribieron su gramática y diccionarios, como por ejemplo también es el caso de la gramática Quéchua del monje dominicano fray Domingo de Santo Tomás (1560). Estos ejemplos demuestran que los españoles en muchos casos no se conformaban solamente con la mera apropiación para satisfacer una curiosidad frente a lo exótico. Según Elliot (1970:35), Sahagún escribe "a highly sophisticated piece of ethnographical field-work", una comparación tan osada entre ambos sistemas religiosos y culturales que llevó a Sahagún frente a la Inquisición con las consecuencias dadas más arriba.

Otro es el caso de Juan López de Velasco en su Geografía y descripción universal de las Indias, escrita entre 1571 y 1574, o el de José de Acosta en su Historia natural y moral delas Indias del año 1590 (vid. "Proemio al Lector" 1590: 9). Ambos registran y describen la otredad, las similitudes y las diferencias en forma decisiva. Fray de Acosta escribe en el "Proemio al Lector":

Mas hasta agora no he visto Autor, que trate de declarar las causas y razón de tales nouedades y extrañezas de naturaleza, ni que haga discurso, è inquisición en esta parte: ni tápoco he topado libro, cuyo argumento sea los hechos y historia de los mismos Indios antiguos y naturales del nuevo orbe (1590: 9).

Elliot resume la suma de este tipo de escritos y testimonios de la época, en particular el trabajo de Acosta, de la siguiente forma:

But Acosta's synthesis was itself the culmination of a century of intellectual endeavour, in the course of which three different aspects of the American world were being slowly and painfully aspects of the European consciousness. America, as an entity in space, had demanded incorporation into Europe's mental image of the natural world. American man had to be found his place among the peoples of mankind. And America, as an entity in time, required integration into Europe's conception of the historical process. All this was achieved during the course of the sixteenth century and it was Acosta's synthesizing genius which brought the great enterprise to completion (1970: 39).

Elliot opina (1970:105), al contrario de Greenblatt, que la Conquista no estuvo determinada solamente por el deseo de la posesión de oro y de la evangelización, sino además por la sed de conocimiento, como se constata en las Cartas de Cortés ${ }^{5}$ y en la crónica de Bernal Díaz del Castillo. A pesar de 
que el utilitarismo se concentra en lo práctico y por ello pasa por alto muchas cosas, Elliot constata que las imposiciones de la Conquista "compelled Europeans to widen their field of vision (sometimes in spite of themselves) and to organize and classify their findings within a coherent frame of thought" (1970: 33).

También el ardiente deseo de cristianizar a los indígenas obliga a algunos monjes a sumergirse en la nueva cultura y a revisar los principios de la propia. Así, Elliot constata:

But inevitability, over the course of the sixteenth century, the increased knowledge and understanding of the indigenous inhabitants of America, and vast differences between them, exposed the inadequacies of the intellectual framework, and forced its modification (1970: 42).

[...]

This process of reappraisal was supremely important, because it gradually forced Europeans to move away from a narrow and primarily political definition of "civility" towards the broader concept of "civilization", which was not necessarily equated with Christianity (1970: 44).

A todo esto se adhiere la discusión si los indígenas eran seres razonables y humanos, disputa que al fin gana Las Casas frente a Sepúlveda partiendo de la alta moral, de la elevada arquitectura y del fino arte, de la organización de la sociedad y comunidad, de su fuerte religiosidad. Todo esto tendrá graves consecuencias que se inscriben en numerosos escritos, como por ejemplo en Delndis (1539) de Victoria. Esta oscilación entre lo extraño y lo propio, entre la aceptación y el rechazo se transforma en un principio de construcción muy consciente, como vemos en los comentarios que hace Alonso de Zorita a la actitud ambivalente de Cortés, quien por una parte alaba la capacidad de los aztecas y por otra los califica de bárbaros. Zorita trata de resolver la contradicción, argumentando que en la Antigüedad se llama bárbaro a quien no hablaba la lengua griega, en este caso, la española.

Estas comparaciones fomentan la introducción de nuevos conceptos de coexistencia, que eran "sufficiently disparate, and sufficiently rich and varied in themselves, to have brought a large number of different, and often incompatible ideas, into uneasy coexistence within a single frame of thought" (Elliot 1970: 47). De esta forma comienzan poco a poco a cambiar los conceptos europeos y sus conceptos de lo bárbaro/salvaje y de lo civilizado.

\footnotetext{
${ }^{5}$ No debe olvidarse que estas cartas también tienen un estatus estratégico: transmitir una imagen positiva de la misión y proteger a Cortés de que se le reprochen avaricia por el oro o la persecución de fines personales a cargo de la corona. Además, las cartas habrían de permitirle entrar a la historia como un caballero heroico.
}

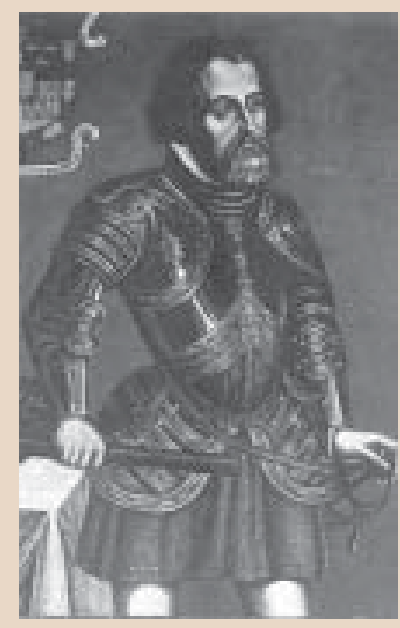

H. Cortés 


\subsection{TOdOROV: LOS DisCURSOS DE LA CONQUISTA COMO CONSTRUCCIÓN DE LA OTREDAD Y EL COMIENZO DE LA HIBRIDEZ}

Todorov considera el Descubrimiento de América no sólo el más grande genocidio en la historia de la humanidad -como apuntábamos más arriba-, sino como el principal acontecimiento de la historia europea que inicia la Edad Moderna y afirma la identidad europea, coincidiendo en ello con O'Gorman (1958) -que ya lo había formulado algunos decenios antes-, y con Elliot, quien afirma que los europeos con el Descubrimiento superan a la Antigüedad que no contaba ni podía competir con semejante acontecimiento. Todorov agrega que "nous sommes tous les descendants directs de Colon, c'est en lui que commence notre généalogie" (Todorov 1982: 14).

Es extraño el gran debate que produjo el libro de Todorov ya que al nivel del objeto, de los hechos a los que se refieren las crónicas, las tesis centrales del trabajo de Todorov están muy bien documentadas en la investigación hace ya mucho tiempo. También la base metodológica con respecto al tratamiento de las crónicas proviene -como dijimos más arriba- de Tropics of Discourse (1978) de Hayden White. Al fin, cierto tipo de interpretaciones y la consideración del nivel representacional son lo que hacen innovador a este libro en varios aspectos y lo que a la vez origina la polémica.

Como indicábamos, Todorov ubica su método de análisis e interpretación de las crónicas entre la novela y la historia (Todorov 1982: 11-12); no le interesa su aspecto empírico, sino el representacional, esto es, en el contexto de la teoría del discurso de Foucault, su lugar de enunciación (Todorov 1982: 60). Semióticamente visto, el aspecto representacional no se puede separar de la perspectiva del narrador (o de los narradores) y forma parte constitutiva de la construcción del mensaje. Con ello, Todorov es el primero en establecer la prioridad de la enunciación y no la del enunciado (aunque no muy consecuentemente).

Todorov también es uno de los primeros en reconocer el rol fundamental de la Malinche como una estructura autónoma en el proceso de la Conquista, y el primero, después de Octavio Paz, en relacionar a la Malinche con la encarnación del métissage, aun cuando incorrectamente asevere que sin la Malinche la conquista de México hubiese sido imposible, ya que olvida que los Tlaxcaltecas, como aliados de Cortés, jugaron un papel primordial:

[...] elle est d'abord le premier exemple, et par là même le symbole, due métissage des cultures; elle annonce par là l'État moderne du Mexique, et au-delà, notre état présent à tous, puisque, à défaut d'être toujours bilingues, nous sommes inévitablement bi- ou triculturelles (Todorov 1982: 107).

Importante es que Todorov, en una forma aún más acentuada y explícita 
que Elliot, no ve la Conquista en sus diversos aspectos siempre en blanco y negro, sino una situación básica que denominamos híbrida. Siguiendo a Elliot, Todorov acentúa, aunque en forma demasiado pronunciada, el deseo de saber de Cortés que no solamente se reduce a la codicia del oro:

Cortés veut d'abord, c'est non pas prendre, mais comprendre; ce sont les signes qui l'intéressent en premier lieu, non leurs référents. Son expédition commence par une quête d'information, non d'or (1982: 105).

Naturalmente que Cortés, un hombre muy táctico, sabe primero apropiarse de los signos e informaciones y traducirlos a sus intereses para conseguir en forma eficaz sus propósitos también pecuniarios. Pero las innumerables negociaciones entre Cortés y los indígenas desde Yucatán hasta Tenochtitlán conducen, a pesar de sus artimañas, a una deterritorialización de Cortés. Particularmente, Cortés desde el primer momento se hace rodear de intérpretes que elige prolijamente y no se contenta sólo con Jerónimo de Aguilar sino hasta que obtiene a la Malinche. Translación es para él la introducción en el Nuevo Mundo, y cuán importante es este proceso en el contexto de una hibridez asimétrica y no intencional lo experimentamos en la varias veces citada Historia verdadera de la Conquista de la Nueva España de Bernal Díaz del Castillo (Díaz del Castillo [1632]1997: 237). En una anécdota en la cual Cortés pone a Orteguilla, que es bilingüe, al servicio de Moctezuma y que se transforma en un verdadero mediador entre las culturas contribuyendo a una situación además de confianza entre ambos grupos:

Y luego Montezuma le demandó a Cortés un paje español que le servía que sabía ya la lengua, que se decía Orteguilla, y fue harto provechoso, ansí para el Montezuma como para nosotros, porque de aquel paje inquiría y sabía muchas cosas de la Castilla el Montezuma, y nosotros de lo que decían sus capitanes, y verdaderamente le era tan buen servicial el paje, que lo quería mucho el Montezuma (Díaz del Castillo [1632]1997: 237).

En un proceso de translación y de hibridación me parece importante la permeabilidad y flexibilidad funcional de los dioses de los aztecas frente al sistema cerrado de la mitología divina cristiana, como alude Todorov (Todorov 1982: 111-112), de tal modo que para los aztecas no era problema incorporar a su mundo los dioses cristianos. Bien conocido es el hecho de que Moctezuma haga construir el Coateocalli, el "Templo de los Dioses" donde se encuentran todos los dioses del reino.

Interesante es la aseveración de Todorov (1982: 115) que la limitada comunicación de los españoles con sus divinidades facilitó la Conquista ya que los aztecas estaban atrapados en su mitología: 


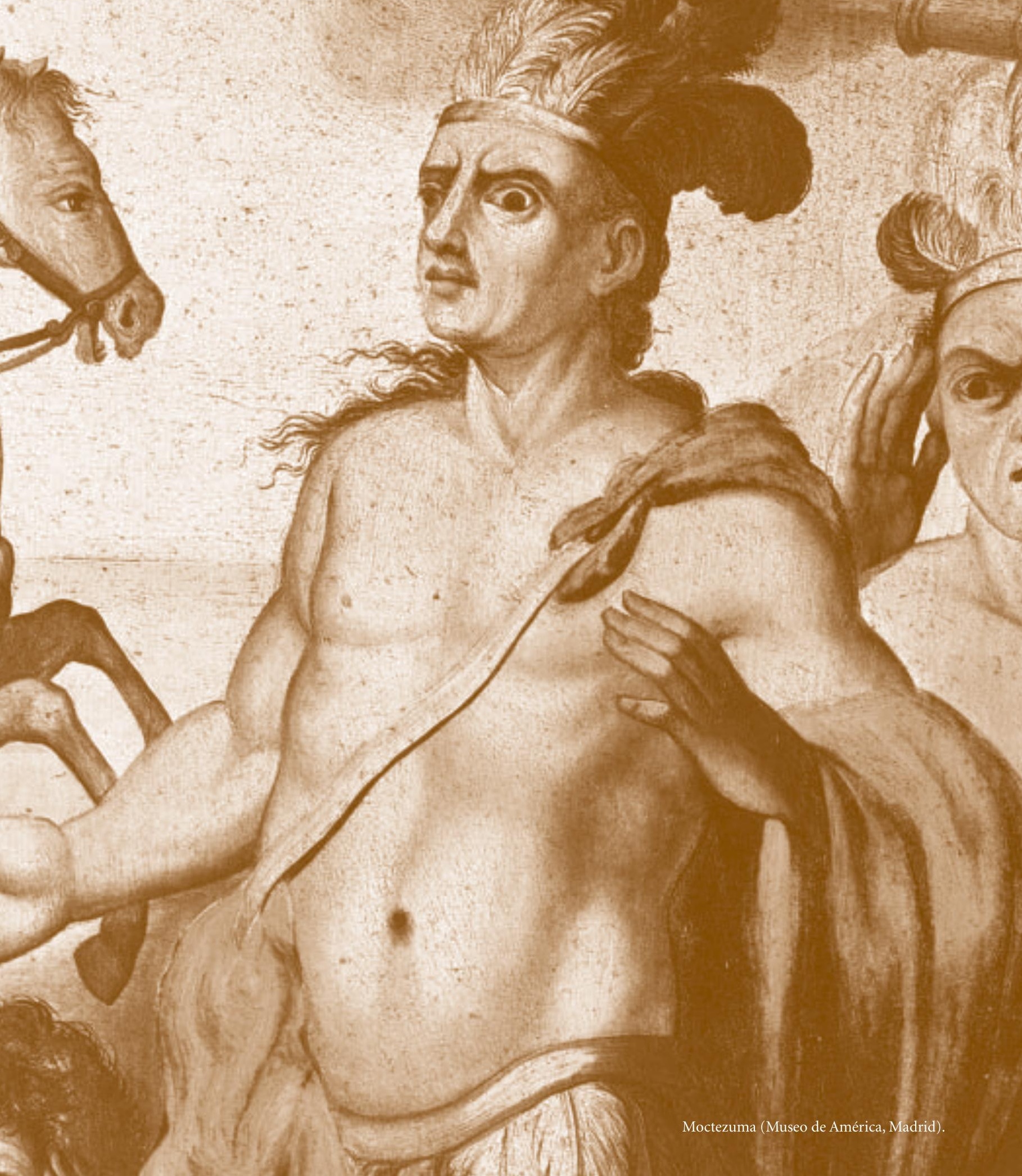


Ce rôle subordonné et finalement limité de l'échange avec Dieu laisse la place à une communication humaine où l'autre sera clairement reconnu (même s'il n'est pas estimé). La rencontre avec les Indiens ne crée pas cette possibilité de reconnaissance, elle ne fait que la révéler (1982: 115).

También la comparación de la cultura azteca con la musulmana y la Antigüedad no son para Todorov (1982: 114), continuando la línea de Elliot, meros actos de canibalismo cultural -como lo entienden Greenblatt y otrossino el comienzo de un proceso ciertamente limitado y asimétrico de la hibridez de una modernidad incipiente.

También la ya mencionada admiración que expresan Cortés y Bernal Díaz frente a la cultura azteca son otro medio de comparación y analogía. Estas comparaciones constituyen frente a la destrucción la paradoja de un espacio híbrido: "Cette comparaison témoignent bien entendu du désir d'appréhender l'inconnu, mai elles contiennent aussi une distribution de valeurs systématique et révélatrice" (1982: 134). Pero Todorov cuestiona esta relación algunas líneas más abajo y la invierte en lo contrario en cuanto la admiración de Cortés no lleva a la aceptación de la diferencia del otro, sino de su aceptación como algo exótico que

[...] touriste d'aujourd'hui, qui admire la qualité de l'artisan quand il voyage en Afrique ou en Asie, sans pour autant que l'idée de partager la vie des artisans qui produisent ces objets ne l'effleure, Cortés est en extase devant les productions aztèques, mais ne reconnaît pas leurs auteurs comme des individualités humains à mettre sur le même plan qui lui (1982: 135).

Siguiendo esta lógica, Cortés y los españoles -así Todorov (1982: 138)no hablan con, sino sobre los aztecas y "comprender" es un acto inservible para Todorov si no va acompañado del reconocimiento -como lo exige también Greenblatt-, cometiendo el mismo error de exigir de los conquistadores una actitud de un teórico de la postcolonialidad en el último tercio del siglo XX. De tal forma que

[...] si comprendre n'est pas accompagné par une reconnaissance pleine de l'autre comme sujet, alors cette compréhension risque d'être utilisée aux fins de l'exploitation, due "prendre"; le savoir sera subordonné au pouvoir (1982: 138),

con lo cual Todorov (1982: 138) contradice sus diferenciadas interpretaciones en dirección de la constitución de un espacio híbrido.

Pero considerando los materiales de las crónicas no se puede sostener que los españoles hablaran sólo sobre los aztecas y no con ellos, al menos 
sabían que estaban hablando con un sujeto comparable a ellos mismos y del que eran altamente dependientes.

Por esto, mi pregunta es si el reclamo tan absoluto de que el acto hermenéutico de comunicación debe ser equivalente con un ilimitado reconocimiento del otro como sujeto, con los mismo derechos, más bien obedece a una actitud moral que tiene que ver con un concepto moderno de los derechos humanos, sin que esto signifique la inexistencia de procesos de hibridación.

La conclusión de Todorov, proveniente de Elliot, es que los españoles estaban dominados por una estrategia de la comunicación regida por intereses utilitaristas, una estrategia de comunicación y de translación con la finalidad de la apropiación de un territorio que luego conduce a la total destrucción, de esta forma coinciden las tesis de Todorov y de Greenblatt.

Finalmente, según Todorov, la destrucción es además una consecuencia de "una sociedad de masacre" (de los españoles) frente a una "sociedad de sacrificio" (de los aztecas) que marcan el comienzo de la Edad Moderna y que son el instrumento primordial de las sociedades colonizadoras.

El genocidio tiene siempre lugar a mucha distancia de las metrópolis colonizadoras, de un centro regido por leyes y moral que en los nuevos territorios no tienen vigencia. Todorov cree, recurriendo al psicoanálisis, que la obsesión sexual (Triebhaftigkeit) del individuo, la agresividad (Agressivitätstrieb), la obsesión de apoderarse de lo ajeno (Bemächtigungstrieb) y su deseo de la muerte (Todestrieb) quedan fuera de quicio, las barreras caen, domina el principio del placer abriéndose las puertas para los sadistas. Esta explicación nos parece plausible si consideramos que muchos de los conquistadores no son de alta alcurnia y su soldadesca aún menos, ya que fueron reclutadas en las clases bajas de la sociedad y en las cárceles.

Mas, otra razón del genocidio es el estatus de animales y esclavos que se les dio a los indígenas (nos referimos sobre todo a Sepúlveda). No fue Victoria en sus Relecciones sobre los indios y el derecho de guerra quien determina esta atribución, sino Aristóteles en la Política:

La relación entre lo masculino y lo femenino es de tal naturaleza que el uno es el mejor y el otro lo menor, uno manda el otro es mandado.

De la misma forma debe suceder entre los seres humanos en general. Aquellos que son tan distantes unos de otros como el alma del cuerpo y del ser humano del animal (esto vale para todos aquellos cuya tarea consiste en el empleo de su cuerpo, que es lo mejor que tienen y que pueden rendir), éstos son los esclavos por naturaleza y para ellos, como para los ejemplos mencionados, es beneficioso que sean mandados.

Por naturaleza es todo aquel un esclavo cuando le pertenece a otro y le pertenece porque tiene acceso a la razón que se le da, pero no le pertenece autónomamente. Los otros seres sirven de tal forma que no reciben la razón, sino que obedecen por sentimientos. Mas su empleo no es muy 
diferente: ambos sirven para realizar un trabajo necesario con el cuerpo, así los esclavos y los animales domesticados (1254b: 15-25, 53-54).

Analizando los métodos de tortura de las tropas norteamericanas en Irak se dieron tres explicaciones posibles: una se basa en los principios de estado de derecho, la segunda en aspectos sociales y la tercera en psicológicos. Cuando un estado de derecho actúa despreciando las instituciones de derecho tanto nacionales como internacionales concede la posibilidad que sus ciudadanos no acepten las reglas establecidas; si un estado de derecho recluta sus soldados en la escoria de la sociedad -como difundieron los medios-, por ejemplo, carceleros brutales, sadistas de todo tipo, etc., no deben sorprendernos las consecuencias y sus excesos; cuando un grupo se encuentra lejos de la patria y bajo órdenes determinadas de emplear la tortura se produce una dinámica de grupo que encauza en una espiral de tortura.

\section{REPRESENTACIONES HIBRIDAS Y ESCENIFICACIONES DE LA OTREDAD EN LAS CRONICAS}

\subsection{La Malinche COMO FIGURA HiSTÓRICO-EPISTEMOLÓGICA Y ENCARNACIÓN DE LA HIBRIDEZ}

La Malinche-hemos indicado- representa el ejemplo más claro de hibridación en la Conquista de México y de América y el "nacimiento" de América, a pesar de ser por otra parte una especie de fantasma. Malinche es -según la descripción de Bernal Díaz del Castillo y su Historia verdadera de la Conquista de Nueva España- un regalo que Cortés recibe como consecuencia de su triunfo en la guerra de Tabasco el 15 de marzo de 1519 junto a otras diecinueve mujeres indígenas con las que los tabascanos reconocen la señoría de Cortés. El origen de la Malinche y su historia personal son inciertos, ya que casi no han quedado vestigios fuera del tiempo que ella pasa con Cortés. Con cierta certeza se sabe que proviene del ámbito de dominio de los aztecas, hablaba Náhuatl y creció en el territorio maya, conociendo también esta lengua. Se sabe que su madre la vendió para asegurar los derechos de herencia de su hijo menor de segundas bodas. De allí en adelante Malinche parece haber sido vendida y revendida de tribu en tribu hasta caer en manos de Cortés y pasar a ser al comienzo uno de los dos intérpretes de Cortés. El otro intérprete es Jerónimo de Aguilar, un náufrago que a partir de 1511 lleva en la isla de Cozumel una vida de esclavo y que habla maya y había perdido casi el español.

El momento inicial de la historia de Malinche se da cuando de Aguilar no es capaz de traducir a Cortés lo que dicen los indios ya que mientras más se acercan a Tenochtitlán más se habla Náhuatl que de Aguilar no domina. 


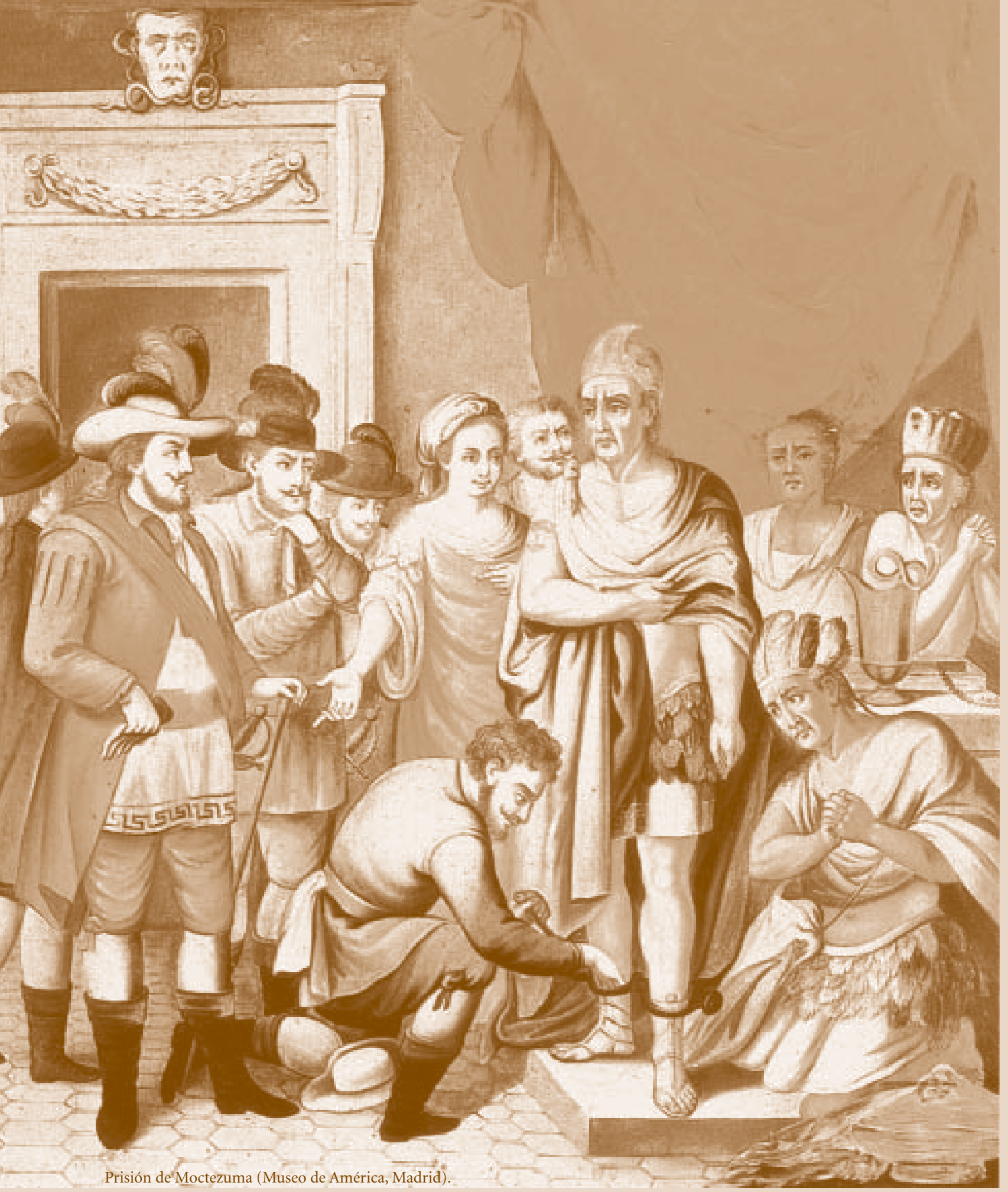


Malinche osa intervenir sin pedir autorización en la conversación entre Cortés y el Cacique tomando el liderazgo de la negociación. Cortés la toma a su servicio, pero se la regala a Alonso Hernández Puerto Carrero y al retornar éste a España, Cortés la hace su amante; una relación de la que nace su primer Martín. Una vez terminada la relación, la casa con Joan Jaramillo, un soldado de su tropa.

Malinche no fue-según Bernal Díaz (como hemos visto según Todorov)una simple amante y una simple intérprete de Cortés, quien luego sin más la "bota" como afirma Greenblatt, sino una gran estratega que tenía una gran reputación, casi divina, en la población indígena y quien gozaba de autoridad y confianza por ambos lados. Malinche se construye como la intersección entre ambas culturas hablando las lenguas del poder: el náhuatl y el español. No había situación en la que ella no estuviese involucrada y en la que no ejerciese su autoridad. Se ve, por ejemplo, que ella es la que aconseja a Moctezuma cuando lo toman prisionero:

[...] y el Montezuma vio a nuestros capitanes como enojados, preguntó a doña Marina que qué decían con aquellas palabras altas, y como la doña Marina era muy entendida, le dijo: "Señor Montezuma: lo que yo os aconsejo es que vais con ellos a su aposento, sin ruido ninguno, que yo sé que os harán mucha honra, con gran señor que sois, y de otra manera aquí quedaréis muerto, y en su aposento se sabrá la verdad (Díaz del Castillo [1632]1997: 235).

La Malinche o la Malintzin (un nombre de origen náhuatl que corresponde en español a 'doña') gozó hasta comienzos del siglo XX de una estupenda reputación. Bernal Díaz es el primero en erigirle un monumento. La llama "Doña Marina" y la describe como la más importante figura de la Conquista:

[...] fue gran principio para nuestra conquista, y ansí se nos hacían todas las cosas, loado sea Dios, prósperamente. He querido declarar esto porque sin ir doña Marina no podríamos entender la lengua de la Nueva España y México (Díaz del Castillo [1632]1997: XXXVII: 101).

[...] y como doña Marina en todas las guerras de Nueva España y Tscala y México fue tan ecelente mujer y de buena lengua, como adelante diré, a esta causa la traía siempre Cortés consigo [...] Y la doña Marina tenía mucho ser y mandaba asolutamente entre los indios en toda la Nueva España (Díaz del Castillo [1632]1997: XXXVII: 101).

La importancia de la Malinche se certifica en cuanto Cortés es llamado "Señor Malinche", con ello pasa a ser la Malinche su voz y su espíritu; ambos llegan a ser una misma moneda con dos caras de la Conquista. 
Cuando Guatemuz, por ejemplo, el sucesor de Moctezuma, es tomado prisionero, éste exige ser llevado frente a Malinche y dice:

No me tire, que yo soy el rey desta ciudad e me llaman Guatemuz; lo que te ruego es que no llegues a cosas mías de cuantas trayo, ni a mi mujer ni parientes, sino llévame luego a Malinche (Díaz del Castillo [1632]1997: CLVI, 447).

Con Todorov compartimos la opinión (que desde la aparición de su libro ha llegado a ser consensual en la investigación) ${ }^{6}$ :

La Malinche glorifie le mélange au détriment de la pureté (aztèque ou espagnole), et le rôle de l'intermédiaire. Elle ne se soumet pas simplement à l'autre [...] elle adopte son idéologie et s'en sert pour mieux comprendre sa propre culture, comme en témoigne l'efficacité de son comportement (même si "comprendre" sert ici à "détruire") (Todorov 1982: 107).

Famoso y relevante es aquel pasaje en H istoria verdadera en el cual Bernal Díaz describe el encuentro de Malinche con su madre y su hermano menor después de tantos años. La descripción es un ejemplo magistral de una traducción híbrida en cuanto se le atribuye a Malinche un discurso y actitud provenientes del viejo y nuevo Testamento y que reproduce el ideal de prudencia y generosidad del "príncipe perfecto". Malinche no solamente perdona a su madre, sino que le quita el miedo, le ofrece su protección y le hace regalos, dejándolos ir con su bendición de paz:

Por manera que vino la madre e su hijo y el hermano, y se conocieron, que claramente era hija suya, porque se le parecía mucho. Tuvieron miedo della, que creyeron que los enviaba hallar para matallos, y lloraban. Y como ansí los vio llorar la doña Marina, les consoló y dijo que no hobiesen miedo, que cuando la traspusieron con los de Xicalango que no supieron lo que hacían, y se lo perdonaba, y les dio muchas joyas de oro y ropa, y que se volviesen a su pueblo; y que Dios la había hecho mucha merced en quitarla de adorar ídolos agora y ser cristiana y tener un hijo de su amo y señor Cortés, y ser casada con un caballero como era su marido Joan Jaramillo; que aunque la hicieran cacica de todas cuantas provincias había en la Nueva España, no lo sería, que en más tenía servir a su marido e a Cortés que cuanto el mundo hay. Y todo esto digo sólo yo muy certificadamente, y esto paresce que quiere remedar lo que le acaeció con sus hermanos en Egito a Josef, que vieron en su poder cuando lo del trigo (Díaz del Castillo [1632]1997: XXXVII, 100).

${ }^{6}$ Cfr. Glantz (1994), Dröscher/Rincón (2001). 
Malinche toma además funciones, en el contexto de la propagación del cristianismo, que están reservadas solamente a sacerdotes:

Y estando Cortés en la villa de Guazacualo, envió a llamar a todos los caciques de aquella provincia para hacerles un parlamento acerca de la santa dotrina, y sobre su buen tratamiento [...] (Díaz del Castillo [1632]1997: XXXVII, 100),

que se reproduce en la iconografía de la época:

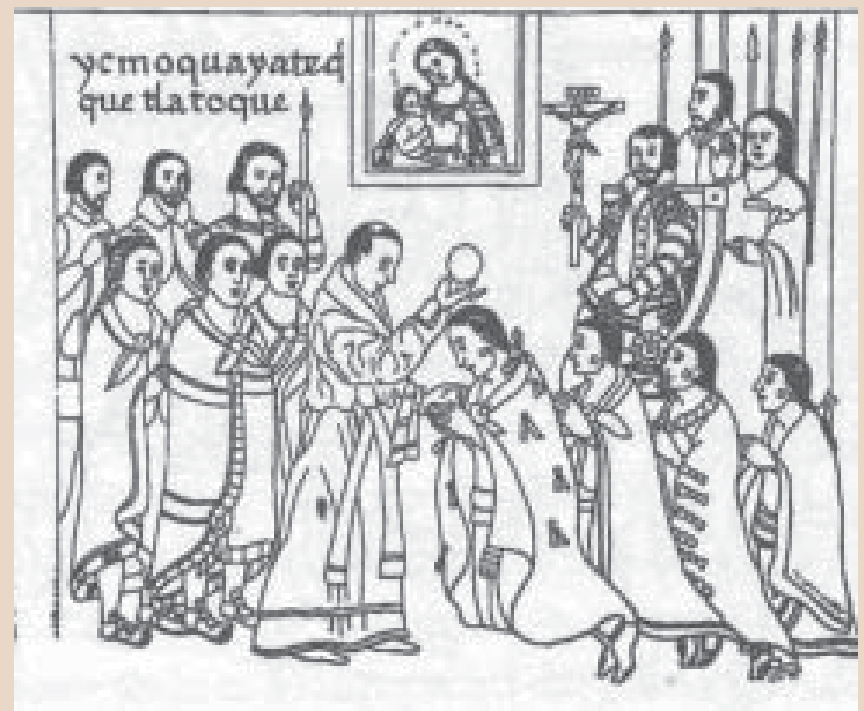

Malinche presencia el bautismo de los tlaxcaltecas con Cortés.

Los lienzos muestran además que Malinche está siempre en primerísimo plano, no solamente en su función de intérprete sino también físicamente ${ }^{7}$ :

${ }^{7}$ Los "lienzos" de Tlaxcala fueron terminados alrededor de 1560. 


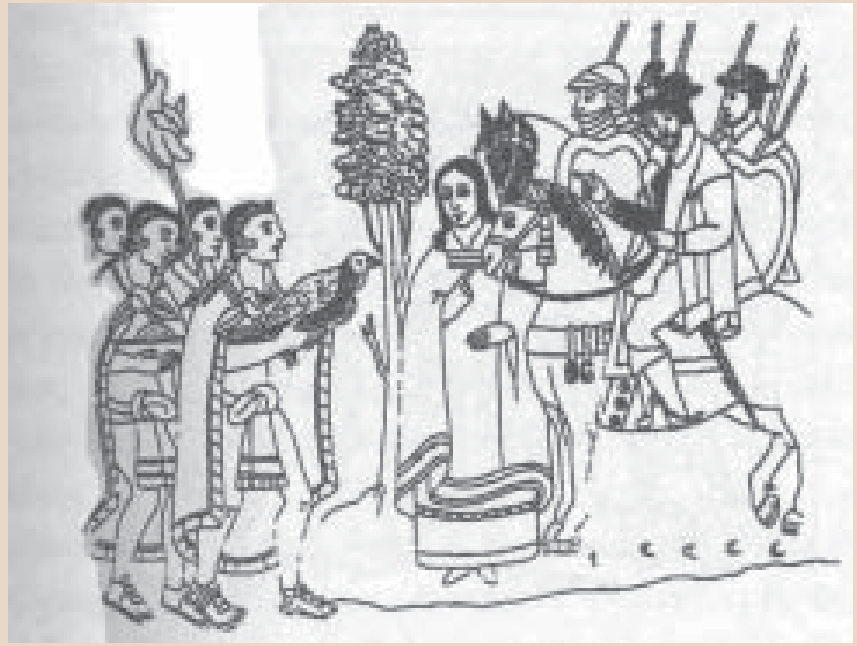

Malinche traduce los regalos de Cortés para los españoles.

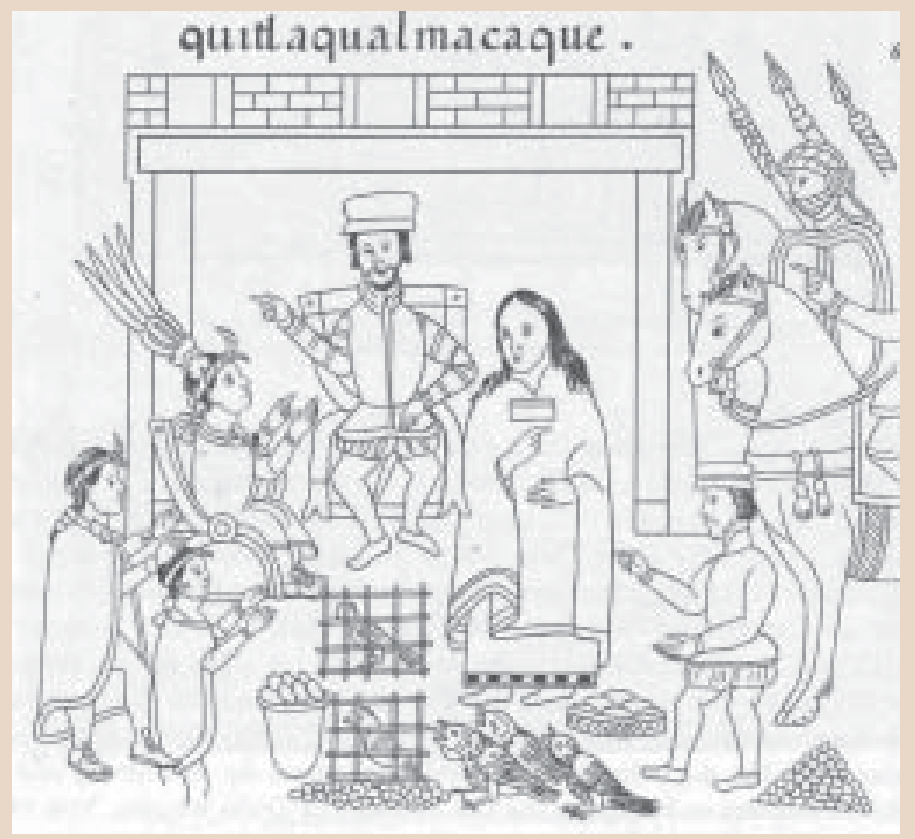

Los tlaxcaltecas proporcionan alimentos a los taxcaltecas.

Malinche es la única que les habla a los reyes (caciques) y al semidios Moctezuma directamente mirándolos a los ojos, lo que para otros significaría la muerte. 


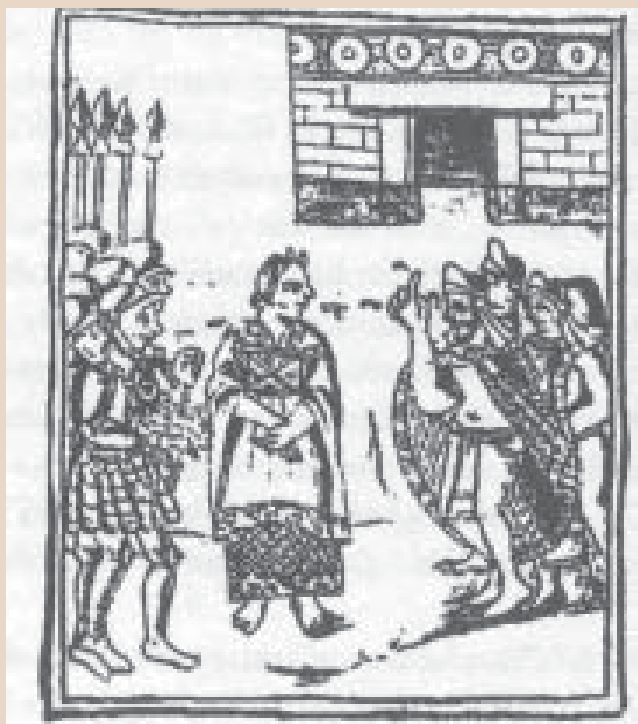

Malinche mira a Moctezuma directo a los ojos.

Malinche se transforma funcional y físicamente en una construcción híbrida que reflejando a María, la madre de Jesús Cristo, no solamente refleja la ambivalencia de las prácticas religiosas, sino también la divinidad de Malinche: la posición de la cabeza de Malinche (a la izquierda) y aquella de la Virgen María (a la derecha) conectan icónicamente ambas figuras:

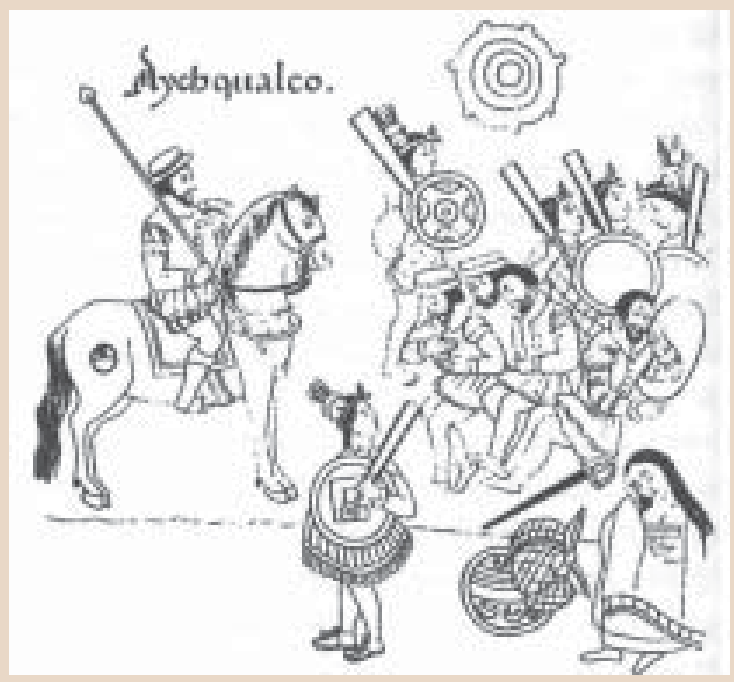

Malinche duerme en el camino a Tenochtitlán. 
Malinche es exactamente lo contrario de Gonzalo Guerrero, el otro náufrago, compañero de Jerónimo de Aguilar que se asimila completamente a la cultura maya y que por sus servicios en la guerra le toman confianza, lo liberan de la esclavitud, asciende a cacique, se casa con una mujer maya y tiene varios hijos. Su apariencia no se distingue en nada de aquella de los mayas.

Malinche representa una figura excepcional y con bastante autonomía en cuanto luchó por encontrar una posición en el incipiente Nuevo Mundo que ella misma está generando, de tal modo que es a la vez víctima y agente y su situación de servir a nuevos señores no es tan distinta a las anteriores. Por el contrario, ella no es solamente la amante del jefe supremo confundido en un principio con Quetzalcóatl, sino que también es su mano derecha e izquierda. Tiene una posición social y política que hasta allí era impensable. Malinche, la mujer en la intersección, era antes de la llegada de los españoles una migrante entre diversos mundos. Ahora aprovecha la oportunidad y conquista poder y prestigio. Malinche es como se constata en la investigación actual la "primera mujer emancipada" del Nuevo Mundo y en la historia moderna. Malinche no fue ni oportunista ni traidora, sino que sitúa y acomoda su interés en un mundo nuevo e irreversible, siendo la primera mestiza, pariendo al primer mestizo, bastardo y chingado, es decir, al primer híbrido.

Frente a este contexto histórico innegable, que se presta como punto de partida para toda ideologización de la identidad y de lo nacional, las palabras de Octavio Paz, citadas más arriba, adquieren una dimensión hasta la fecha inesperada.

Paz es el primer intelectual latinoamericano que conecta el término 'chingado' con la Malinche en un contexto histórico y en una forma constructiva, sin ponerla en un plano negativo. Por lo demás, Sor Juana Inés de la Cruz es, como Martín, una bastarda cuya madre ni siquiera se sabe bien quién es; por esto, Sor Juana es para Octavio Paz la encarnación de la hibridez. Es el primero en poner a la Malinche en un pedestal y reclamarla como la figura de la Conquista y como la base para la construcción de la historia y de la identificación de Latinoamérica, más allá de esencialismos y hegemonías.

En este lugar no puedo entrar en detalle a las tan controvertidas tesis de Octavio Paz con respecto a México, pero basándome en algunas observaciones incito a una nueva lectura de Paz, quien con su posición se encuentra mucho más adelantado que las teorías culturales de la época y más bien encaja en los teoremas de la postcolonialidad y del principio de pluralidad postmoderna. La 'soledad' de la que habla Paz tiene su origen, por una parte, en la negación y en el encubrimiento de la propia historia e identidad, a través de la adopción de conceptos europeos y de la nostalgia de la cultura 
precolombina; por otra parte, bajo 'soledad' se puede entender otra denominación para hibridez, para un mundo de pasajes representado por la Malinche, personaje a quien se le atribuye el rol de la traicionera y de negación del mexicano a comienzos del siglo XX, como consecuencia de un nacionalismo esencialista que, según Paz, deja a México fuera de la historia. Malinche se transforma de pronto en malinchismo, en un término peyorativo, equivalente a extranjerizante y traicionero, que tiene como punto de partida el sangriento y difuso episodio de Cholula y la primera masacre cometida por Cortés en México.

En el ensayo mencionado, Paz reintroduce a México en el proceso histórico con Malinche en el centro. Lo que Paz hace en el muy discutido ensayo es ofrecer una radiografía de las opiniones sobre un México que se hallaba en una calle sin salida para encontrar un alternativa. México -según Paz- se encuentra volcado y encerrado en sí mismo, con ello se excluye México no solamente del presente y del futuro, sino de su pasado y de allí la fórmula: "Nuestro grito es una expresión de la voluntad mexicana de vivir encerrados al exterior, sí, pero sobre todo, cerrados frente al pasado" (Paz 1950: 78). La alternativa o solución la ve Paz en el reconocimiento del pasado acuñado por la Malinche, por la 'chingada', en breve, en la hibridez: "En ese grito condenamos nuestro origen y renegamos de nuestro hibridismo" (1950: 78). Ese 'hibridismo' que representan tanto Cortés como Malinche ha sido 'tabuizado' y silenciado, encubierto y negado y de esta forma las posibilidades de identidad, nación e historia:

La extraña permanencia de Cortés y de la Malinche en la imaginación y en la sensibilidad de los mexicanos actuales revela que son algo más que figuras históricas: son símbolos de un conflicto secreto, que aún no hemos resuelto. Al repudiar a la Malinche -Eva mexicana, según la representa José Clemente Orozco en su mural de la Escuela Nacional Preparatoria- el mexicano rompe sus ligas con el pasado, reniega su origen y se adentra solo en la vida histórica (Paz 1950: 78).

En este caso tenemos un bloqueo que no admite una condición híbrida, una historia de mezclas de culturas que es la herencia de México, su historia misma: "El mexicano condena en bloque toda su tradición, que es un conjunto de gestos, actitudes y tendencias en el que ya es difícil distinguir lo español de lo indio" (Paz 1950:78).

Este bloqueo es parte de una ideología esencialista o hegemónica propagada por indigenistas o por los europeizantes; ambos grupos son rechazados por Paz:

Por eso la tesis hispanista, que nos hace descender de Cortés con exclusión de la Malinche, es el patrimonio de unos cuantos extravagantes -que 
ni siquiera son blancos puros-. Y otro tanto se puede decir de la propaganda indigenista, que también está sostenida por criollos y mestizos maniáticos, sin que jamás los indios le hayan prestado atención. El mexicano no quiere ser indio, ni español. Tampoco quiere descender de ellos. Los niega (Paz 1950: 78).

Pero no solamente Malinche es una figura híbrida, sino evidentemente también Jerónimo de Aguilar. Bernal Díaz nos da una impactante descripción de la primera vez que lo encuentran. Aguilar camina por un momento en el séquito de Cortés, prácticamente a su lado sin ser reconocido; cuando Cortés pregunta donde éste se encuentra, Aguilar se presenta a Cortés tomando la postura típica indígena, poniéndose en cuclillas enfrente con el remo sobre el hombro, y dice: "yo soy", lo que lo define como un sujeto occidental-cristiano tan diferente al yo del sujeto precolombino:

“¿Qué es del español?”, e aunque iban junto con él, porque le tenían por indio proprio, porque de suyo era moreno y tresquilado a manera de indio esclavo, y traía un remo al hombro, una cotara vieja calzada y la otra atada en la cintura, y una manta vieja muy ruin, e un braguero peor, con que cubría sus vergüenzas, y traía atada en la manta un bulto que eran Horas muy viejas. Pues desque Cortés los vio de aquella manera también picó, como los demás soldados, que preguntó al Tapia que qué era del español: y el español, como le entendió, se puso encuclillas, como hacen los indios, e dijo: 'Yo soy'. (Díaz del Castillo [1632]1997: XXIX, 84).

\subsection{Translación: Comparación - Analogía: Hibridez}

Más arriba dijimos que la translación se valía de las estrategias retóricas de la comparación y de la analogía construyendo un objeto híbrido.

Queremos completar nuestros ejemplos con algunos pasajes de las obras de Bernal Díaz del Castillo en H istoria verdadera de la Conquista dela Nueva España y de Las Casas en Apología e H istoria delas Indias de Nueva España e Islas deTierra Firme. Otros autores serían Sahagún, Muñoz Camargo, Alvar Ixtilxóchitl, Bautista Pomar, Alvarado Tezozomoc, Pachacuti o el Inca Garcilaso.

En H istoria de Bernal Díaz encontramos un párrafo donde se compara a la Virgen María con las "teleciguatas", esto es, con "mujeres famosas de la región":

Y luego los casiques mandaron llamar a todos los vecinos, y con sus hijos y mujeres en dos días se pobló: y lo otro que les mandó, que dejasen sus ídolos y sacrificios, y respondieron que ansí lo harían; [...] y se les mostró 
una imagen muy devota de Nuestra Señora con su hijo precioso en los brazos, y se les declaró que en aquella santa imagen reverenciamos, porque ansí está en el cielo y es madre de Nuestro Señor Dios. Y los caciques dijeron que les parescía muy bien aquella gran teleciguata, y que se la diesen para tener en su pueblo, porque a las grandes señoras en aquella tierra, en su lengua, llaman teleciguatas (Díaz del Castillo [1632]1997: XXXVI: 97).

Tenemos por una parte la descripción de monstruos y salvajes, homosexuales y sodomitas, sacrificadores de víctimas humanas y caníbales:

[...] y que también había de ser limpios de sodomía, porque tenían muchachos vestidos en hábitos de mujeres que andaban a ganar en aquel maldito oficio, y cada día sacrificaban delante de nosotros tres o cuatro o cinco indios, y los corazones ofrecían a sus ídolos, y la sangre pegaban por las paredes, y cortábanles las piernas y los brazos y muslos y lo comían como vaca que se traen de las carnicerías en nuestra tierra y aun tengo creído que lo vendían por menudo en los tianguis, que son mercados (Díaz del Castillo [1632]1997: LI: 128),

y como altamente civilizados y dignos de admiración: “[... y es admirada y comparada con Venecia, Constantinopla y Roma" (Bernal Díaz H istoria verdadera [1632] 1997:224-238). La admiración se expresa intensamente cuando Bernal Díaz alaba la maestría de los oficios de artesanía de "lapidarios y plateros de oro y plata" que es tal "que en nuestra España los grandes plateros tienen que admirar en ellos [...] muchos grandes maestros" (Díaz del Castillo [1632]1997: 220), así también "pintores sublimados como los indios que se dicen Marcos de Aquino y Joan de la Cruz, y el Crespillo, que si fuesen en el tiempo de aquel antiguo o afamado Apeles, o de Micael Angel, o Berruguete, que son de nuestros tiempos, también les pusieran en el número de ellos" (Díaz del Castillo [1632] 1997: 220). Las expresiones de 'que se dicen' y 'si fuesen en el tiempo de aquel antiguo o afamado' marcan la translación por la vía de la comparación y de la analogía. El producto híbrido se refleja además en los atributos y en los nombres, tales como Marcos de Aquino y Joan de la Cruz, y el Crespillo o 'pintores sublimados' que hacen un arte maestro. 'Arte' es aquí arte y sin una carga exótica, sino que por similitud en la perfección y no en el tipo de expresión y esta percepción equivalente refleja un cambio de valorización por parte de Bernal Díaz.

En el campo lingüístico topológico encontramos una cantidad de nombres creados para designar regiones o ríos descubiertos, o la descripción de ritos religiosos, comidas y vestuario, etc. Los españoles crean la topografía a través de la palabra: "Como habían tantos caimanes le llamamos el río de los caimanes".

Detengámonos en las comidas que son parte de la maravilla: "treinta 
maneras de guisados"; "más de trescientos platos" y "más de mil para la gente de guarda" (ibíd.: 216). Este refinamiento se enturbia con la mención del canibalismo que también cometen los españoles ya que no son capaces de distinguir entre carne de pollo y de ser humano. Por esto, Cortés le ruega encarecidamente a Moctezuma que abandone semejantes prácticas y que prohíba la venta de carne humana en el mercado:

Oí decir que le solían guisar carnes de muchachos de poca edad, y como tenía tantas diversidades de guisados y de tantas cosas, no lo echábamos de ver si era de carne humana o de otras cosas, porque cotidianamente guisaban gallinas [...] E ansí no miramos en ellos: mas sé que ciertamente desque nuestro capitán reprehendía el sacrificio y comer de carne humana, que desde entonces mandó que no le guisasen tal manjar (Bernal Díaz: Historia verdadera 1632/1992: 216-217).

En otro lugar, Bernal Díaz pone en claro que son los "papas" quienes comen carne de niños sacrificados, manifestándose asíla ignorancia de Bernal Díaz con respecto al canibalismo ritual practicado tan sólo por los "papas", y quizás por Moctezuma señor de los "papas", que comían ciertas partes del cuerpo de la víctima sacrificada.

Tanto Tenochtitlán como la figura de Moctezuma son motivo de una admiración sin límites. A Moctezuma se le describe como un verdadero soberano, una mezcla entre dios y rey y de apariencia sublimada: "de buena estatura e bien proporcionado" (Díaz del Castillo [1632]1997: 216). Su vestimenta, comportamiento e higiene producen un impacto en Bernal Díaz: “[...] bañábase cada día una vez, a la tarde, cambiaba constantemente de ropas" (Díaz del Castillo [1632] 1997: 216). También su vida matrimonial es motivo de admiración y asombro ya que se trata de relaciones altamente ritualizadas, como también lo son sus comidas. La fórmula que Bernal Díaz aplica y que sintetiza toda su admiración es: "El gran Montezuma” (Díaz del Castillo [1632]1997: 216).

Particularmente impresionante es la descripción de Bernal Díaz del primer rencuentro entre Cortés y Moctezuma en Coyoacán. Este va bajo un "palio adornado con oro, plata y piedras preciosas", sus zapatillas ("cotaras") están adornadas con joyas y tienen una suela de oro, sus vestimentas son de un arte refinado: "rica manera de vestidos a su usanza". Bernal Díaz describe cómo los sirvientes van barriendo el suelo por donde ponen una alfombra por la que se desplaza Moctezuma, quien apoyado en sus brazos parece volar, nadie le puede mirar a los ojos y una infracción está penada a muerte (Díaz del Castillo [1632]1997: LXXXVIII: 210-211).

Estos ejemplos revelan un proceso de hibridación que se escapa a las intenciones de evangelización y de subyugación o muerte; el proceso está en marcha y es inevitable. 
Otra escena singular es la descripción del tipo de relaciones entre Cortés y Moctezuma. Cortés debía conservar un espacio frente al rey azteca ya que de otra forma se "lo tenían por menosprecio" (ibíd.). Cortés -luego de haber visitado el Templo Mayor- quiere obligar a Moctezuma a abandonar los dioses sangrientos; Moctezuma, indignado, le responde que sus dioses son tan buenos como los del Señor Malinche y que con esto se acaba el problema. Cortés se calla y acepta el reto "cara alegre", despidiéndose con una disculpa: Y Cortés le dijo: "Pues que ansí es, perdone, señor" (ibíd.: 227).

Más tarde, cuando los españoles temen la subversión de los príncipes aztecas y toman preso a Moctezuma en su propio palacio, le dejan sus privilegios y libertades, como por ejemplo, jugar a la pelota o ir a orar a Vichilobos (ibíd.: 238-245ss.).

Bernal Díaz subraya constantemente el intercambio de "cortesías" y de "amor" entre ambos señores. Su crónica contiene escenas realmente conmovedoras, cuya base empírica no podemos poner en duda ni confirmar, por ejemplo, cuando Bernal Díaz describe los sentimientos que ambos señores sienten recíprocamente (Díaz del Castillo [1632]1997: 237, 265). Aunque el texto de Bernal Díaz naturalmente está empeñado en describir a Cortés y a los españoles (como también a sí mismo) y en darle a la Conquista un rostro más humano, su discurso contiene una serie de pasajes que no mantienen esta línea. Por ejemplo, cuando Bernal describe los conflictos entre Cortés y los indígenas y la brutalidad de su proceder o cuando discute con Moctezuma, salen a luz los conflictos internos en los determinados grupos (Díaz del Castillo [1632]1997: 117, 119-122). Bernal Díaz nos informa cómo Cortés y Moctezuma saben usar para sus propios intereses los enemigos y las debilidades que cada uno tiene por su parte (Díaz del Castillo [1632]1997: 188).

A pesar de la repulsión que le provocan los rituales y sacrificios religiosos de los aztecas, Bernal Díaz inicia un proceso de translación e hibridación sin par. Compara la incineración de resina para la adoración de los dioses aztecas con el incienso de los rituales cristianos, que también se da en otros textos y crónicas, como por ejemplo en $\mathrm{H}$ istoria general delas cosas de Nueva España de Sahagún o en H istoria delas Indias deN ueva España elslas deTierra firme de Durán, en Relación de Yucatán de Landa o en Naufragios de Alvar Núñez. Este último, un complejo ejemplo de hibridez, se encuentra entre Gonzalo Guerrero y Jerónimo de Aguilar como esclavo de los indios de Florida por más de siete años, se transforma en una especie de chamán y Cristo que salva a enfermos y hace revivir a muertos (el caso de Lázaro) traduciendo, es decir, combinando o reemplazando los métodos indígenas de "unas sajas donde tiene el dolor" o "chúpanles alrededor de ellas. Dan cauterios de fuegos", por "curamos antiguándonos y soplarlos y rezar un 'Pater Noster' y un 'Ave María', rogar lo mejor que podíamos [...] y luego que los santiguamos decían a los otros que estaban sanos y buenos". 
Otro aspecto de la hibridación lo constituye el término "poblar". En un sentido evangélico, "poblar" significa llevar la palabra de Cristo y aumentar la fama de Carlos V. Sin embargo, "vayan a poblar" experimenta una extensión en el sentido de mezcla étnica, es decir, implica el amancebamiento o matrimonio con mujeres indígenas. Cuando Cortés recibe de regalo veinte mujeres en Tabasco, Bernal Díaz las hace instruirse primero en el catecismo y luego las hace bautizar, finalmente se las da a los soldados para que las desposen y convivan con ellas: "Estas fueron las primeras cristianas que hubo en la Nueva España", y los caciques "fueron los primeros vasallos que en la Nueva España dieron obediencia a Su Majestad” (ibíd.: 98).

Cuando Las Casas, por ejemplo, reconoce en los indígenas un temperamento virtuoso y una disposición religiosa más ejemplar que la de los españoles para aceptar el cristianismo, esta descripción y admisión de los indígenas como criaturas dignas de Dios es, a pesar de su perspectiva unilateral, un primer paso a los derechos universales de los derechos del hombre, basándose en la dignidad indígena, concepto que no se habría dado sin el Descubrimiento.

Tanto Bernal Díaz del Castillo como Alvar Núñez Cabeza de Vaca describen el Descubrimiento y la Conquista como el infierno para ambas culturas, pero también como una nueva civilización. De igual manera lo expresa Carlos Fuentes en boca de Jerónimo de Aguilar en El naranjo:

Lo cierto, empero, es que los españoles sacrificados por los mayas en los altares de Valladolid y Burgos, en las plazas de Cáceres y Jaén, tuvieron la distinción de morir ingresando a un rito cósmico y no, como pudo sucederles, por una de esas riñas callejeras tan habituales en España. O, para decirlo con símil más gastronómico, por una indigestión de cocido. Es cierto que esta razón fue mal comprendida por todos los humanistas, poetas, filósofos y erasmistas españoles [...] (El naranjo 1993/121999: 55$56)$.

La difícil y compleja distribución de la ambivalencia es una de las razones por las cuales la historia hasta la Modernidad, encasillada en un binarismo de corte racionalista y empirista y al fin moralizante, no tuvo los instrumentos que se han dado con las lecturas de orientación postmoderna y postcolonial. La Ilustración con un concepto de razón y lógica cartesiana y kantiana que se concretiza en el cientismo decimonónico bloqueó la posibilidad de captar esa lógica y racionalidad diferente que se genera con el Descubrimiento, donde los objetos y los textos sobrepasaban las clasificaciones que hasta entonces se tenían a disposición. Allí radica, a mi parecer, la fundamental importancia de los ensayos de Montaigne "Des cannibales" ([ca. 1579]/1965/21992: cap. XXXI, vol. I, pp. 202-215) y “Des Coches", (cap. XXXII, pp. 898-914), a los que en esta ocasión no puedo entrar detalladamente. Por 
ello me permito tan sólo indicar cómo en relación con este texto se forman diversas posiciones. Mientras Gewecke (1986: cap. VII) ve un primer intento de captar la otredad, Rincón (1990: 221-222) excluye esta posibilidad con el argumento de que tanto él como Las Casa u otros usan el reproche o la comparación para criticar el fracaso de sus propias instituciones.

\section{RESUMEN}

"Latinoamérica" ha sido desde 1492 un campo privilegiado para todo tipo de experimentos culturales, de donde han resultado modelos de acción y de coexistencia transcultural que se prestan como ejemplos para otras regiones y constelaciones.

Para poder apreciar la dimensión del conflicto civilizatorio y el aporte que hicieron los cronistas, tales como Sahagún, Oviedo, Durán y tantos otros españoles, esto es, conquistadores, monjes, aventureros, científicos, etnógrafos, que creyeron llegar a un paraíso, donde habían constantemente guerras, donde regía un régimen del terror, donde habían sacrificios humanos y hasta canibalismos rituales, pero a la vez una floreciente cultura, debemos abandonar la idea del imperio de un discurso hegemónico unilateral y más bien ubicar este discurso en una estrategia discursiva híbrida de la "no simultaneidad de lo simultáneo" (Rincón 1995). Solamente así se revelan los puntos de ruptura en las intersecciones de donde nace un nuevo modelo civilizatorio y el inicio de la modernidad.

Futuras investigaciones deberán demostrar que los españoles, tan demonizados por las diversas leyendas negras, hicieron un aporte hercúleo al inicio de la época Moderna ya que con el Descubrimiento todas las categorías y todo el conocimiento hasta allí existentes pierden en parte su vigencia.

El concepto de hibridez, como resultado de un proceso de translación basado en la comparación, similitud y analogía, se presta como un instrumento para investigar el Descubrimiento y la Conquista, más allá de conceptos binarios, en cuanto nos permite distinguir entre los hechos, la moral de los hechos y su nivel representacional, es decir, su escenificación sígnica.

La permanente oscilación entre lo antiguo y lo nuevo, lo extraño y lo propio, la destrucción y la construcción, el rechazo y el reconocimiento, nos demuestra que el Descubrimiento y la Conquista de América no se pueden reducir solamente a su destrucción, como particularmente Greenblatt en M arvelous Possessions (1991) o Subirats en El continente vacío (1994) afirman. No solamente el mestizo Garcilaso el Inca fue un pasajero entre las culturas, sino también, entre otros, los cronistas de origen indígena o mestizos, Santacruz Pachacuti, Alva Ixtlixóchitl y muchos otros cronistas españoles; en la suma de los escritos se constata la construcción de un nuevo mundo. 
Los textos, por ejemplo, las crónicas o relaciones eran en sí de carácter híbrido: una mezcla entre autobiografía, testimonio, reportaje empírico, historia, etc. Estos textos y muchos otros hacen la primera contribución a un proceso de hibridación.

La oportunidad de construir una sociedad transcultural en la Península Ibérica fue desperdiciada con la famosa Reconquista, que culmina con la expulsión de los "moros" y "judíos" en 1492 y que se desperdicia en parte en el Descubrimiento; pero solamente en parte ya que se genera una nueva cultura.

La necesidad de releer las crónicas bajo el aspecto de la hibridez nos debe también demostrar cuáles fueron las carencias y las pérdidas del Descubrimiento y la Conquista. Comparar las carencias y las pérdidas de oportunidades de entonces con las de hoy en día frente a gigantescas migraciones que rompen con todas las categorías habituales hasta ahora, nos muestra que los españoles y los europeos se encontraban en 1492 en una situación similar a la de hoy, aunque en una dimensión muchísimo más compleja a la nuestra.

\section{BIBLIOGRAFIA}

\section{TeXtos}

Acosta, Padre Joseph de. 1590/6 1792/1987. H istoria natural y moral delas Indias. Madrid. Por pantalón Aznar/Sevilla, Edición Hispano-America de Publicaciones/Santacruz Pachacuti.

Alva Ixtlixóchitl, Fernando de. ca. 1610-1650/2000. Historia de la nación chichimeca. Ed. de Germán Vázquez Chamorro. Madrid: Dastin.

Aristoteles. ${ }^{6} 1986$. Politik, München: DTV.

Cortés, Hernán. 1770/1970/1993. Cartas dela Relación dela Conquista de M éxico. Edición, introducción y notas de Angel Delgado Gómez. Madrid: Castalia.

Díaz del Castillo, Bernal. $1632 /{ }^{10} 1997$. Historia verdadera de la conquista de la Nueva España. Madrid: Austral.

Dröscher, Barbara/Rincón, Carlos. (eds.) 2001. La Malinche. Ü bersetzung, Interkulturalität und Geschlecht. Berlin: Tranvía.

Durán, Fray Diego. 1867-1880/1967/21984. Historia de las Indias de Nueva España elslas deTierra firme, vols. I y II. México: Porrúa.

Fernández de Oviedo y Valdés, Gonzalo. 1526/2002. Sumario de la natural historia delas Indias. Edición de Manuel Ballesteros Gaibrois. Madrid: Dastin.

Fernández de Oviedo y Valdés, Gonzalo. 1535/1959. Historia general y natural de las Indias, islas y tierra-firme del mar océano. Biblioteca de Autores Españoles, tomo CXVII-CXX. Edición y estudio preliminar de Juan Pérez de Tudela y Bueso. Madrid: Atlas.

Fuentes, Carlos. 1993/121999. El naranjo. México: Alfaguara.

Garcilaso de la Vega. 1605/1970. H istoria dela Florida. O bras Completas del Inca 
Garcilaso, vol. I, B, en Biblioteca de Autores Españoles CXXXII. Edición y estudio preliminar de P. Carmelo Sáenz de Santa María. Madrid: Atlas, pp. 241-526.

Garcilaso de la Vega, el Inca. 1609/1963. Comentarios Reales de los Incas. O bras Completas del Inca Garcilaso, vol. II, en Biblioteca de Autores Españoles CXXXIII. Edición y estudio preliminar de P. Carmelo Sáenz de Santa María. Madrid: Atlas, pp. 7-385.

Garcilaso de la Vega, el Inca. 1617/1960. H istoria general del Perú. Segunda parte delos Comentarios reales de los Incas. O bras Completas del Inca Garcilaso, vol. III, en Biblioteca de Autores Españoles CXXXIV. Edición y estudio preliminar de P. Carmelo Sáenz de Santa María. Madrid: Atlas, pp. 7-402.

Guamán Poma de Ayala, Felipe. 1615/1987. El primer nueva crónica y buen gobierno, Ed. de John V. Murra \& Rolena Adorno. vol. A-C. México: Siglo XXI.

Landa, Diego de. 1985. Relación de Yucatán. Madrid: Historia 16.

Las Casas, Fray Bartolomé de. 1542/1552/ ${ }^{10} 1996$. Brevísima relación de la destrucción de las Indias. Madrid: Cátedra.

Las Casas, Fray Bartolomé de. 1998. O bras Completas, vols. 1-14. Madrid: Alianza. Lazarillo de Tormes. 1554/11 1983 . Madrid: Cátedra.

López de Gómara, Francisco. 1943. H istoria dela Conquista de M éxico, vols. I-II Introducción y notas de Joaquín Ramírez Cabañas. México: Pedro Robredo.

Motolinía, Fray Toribio de. 1985. H istoria de los Indios dela Nueva España. Edición de Georges Baudot. Madrid: Castalia.

Núñez Cabeza de Vaca, Alvar. 1542/52001. Naufragios, Madrid: Cátedra.

Pérez de Oliva, Fernán. 1528/1993. H istoria de la invención de las Yndias. H istoria de la conquista de la Nueva España. Edición de P. Ruiz Pérez. Córdoba: Universidad de Córdoba.

Sahagún, Bernardino de. 1569/1990. H istoria general delas cosasdeNueva España, Edición de Juan Carlos Temprano, vols. I-II. Madrid: Historia 16.

Santacruz Pachacuti, Yamqui, Joan de. 1613/1950. Tres relaciones de antigüedades peruanas. Asunción del Paraguay: Guarani, pp. 207-281.

Sepulvedae Cordvbensis, Io. Genesii. 1993. De rebvs hsipanorum ad novvm terrarvm orbem mexicvmqve gestis (De orbe Novo), Ed. de Antonio Ramírez de Verger. Stvtgardiae et Lipsiae, In Aedibvs B.G. Tevbneri.

Sepúlveda, Juan Ginés de. 1521/1987/21996. H istoria del Nuevo M undo. Introducción, traducción y notas de Antonio Ramírez de Verger. Madrid: Alianza.

Testimonios, cartas y manifiestos indígenas (Desde la Conquista hasta comienzos del siglo XX). Selección, prólogo, notas, glosario y bibliografía de Martin Lienhard. Caracas: Biblioteca Ayacucho.

Victoria, Franciscus de. 1539. Delndis recenter inventis et de jure bellis et dejure belli Hispanorum in barbaros. Edición y traducción al alemán de Walter Schätzel (1952). Tübingen: J.C.B. Mohr (Paul Siebeck).

Zorita, Alonzo de. 1909. Historia de la Nueva España, vol. I (The only one published). Madrid, pp. 122-30.

Zorita, Alonzo de. sf/1963/1994. Lifeand labor in Ancient M exico. The Brief and Summary Relation of the Lords of New Spain. Norman/London: University of Oklahoma Press. 


\section{CRÍTICA}

Alarcón, Norma. 1983. "Chicana’s Feminist Literature: a re-vision through Malintzin / or Malintzin: Putting Flesh Back on the Object", en Cherrie Moraga/Gloria Anzaldúa (eds.).ThisBridge Called M y Back. New York: Kitchen Table Press, pp. 183-190.

Alarcón, Norma. 1989. “Traddutora, Traditora: A Paradigmatic Figure in Chicana Feminism", en Cultural Critique 13, pp. 57-87.

Bhabha, Homi K. 1994. The Location of Culture. London: Routledge.

Bennassar, Bartolomé. 2001/2002. Cortez der Konquistador. Die Eroberung des Aztekenreiches. Düsseldorf/Zürich: Artemis \& Winkler.

Castellanos, Rosario. 1975/1987. El eterno femenino. Farsa. México: Fondo de Cultura Económica.

Corpi, Lucha. 1978. "Las poemas de Marina / The Marina Poems”, en Roberta Fernández 1994: In Other Words Literature by Latinas in the U.S. Houston: Arte Público Press, pp. 54-55.

Derrida, Jacques. 1996. Le monolinguisme de l'autre. Paris: Galilée.

Elliot, John H. 1970. The Old World and the New. Cambridge: University Press. Fanon, Frantz. 1952/21975. Peau noir masques blancs. Paris: Seuil.

Friedman, John Block. 1981. TheM onstruousRacesin M edieval Art and Thought. Cambridge: Harvard University Press.

Gewecke, Frauke. 1986. Wie dieneueWelt in diealtekam. Stuttgart: Klett-Cotta.

Glantz, Margo (ed.). 1994/2001. La Malinche, sus padres y sus hijos. México: UNAM/Planeta.

Greenblatt, Stephen. 1991/22001. M arvelous Possessions. The Wonder of the N ew World. Chicago: University of Chicago Press.

Gyurko, Lanin A. 1977. “The Vindication of La Malinche in Fuentes' Todos los gatos son pardos”, en Ibero-Amerikanisches Archiv, Jg.2, Heft 3, pp. 233-266.

Maravall, José Antonio. 1966. Antiguos y modernos. Madrid: Sociedad de Estudios.

Montaigne, Michel de. ca.1579/1965/21992. “Des cannibales”, cap. XXXI, vol. I, pp. 202-215; "Des Coches", cap. XXXII, pp. 898-914, in: Ders. Les Essays. Paris, Quadrige/PUF.

O’Gorman, Edmundo. 1958. La invención de América. El universalismo de la cultura de O ccidente. México/Buenos Aires: Fondo de Cultura Económica.

Paz, Octavio. 1950/³1973. El laberinto dela soledad. México: Fondo de Cultura Económica.

Phillips, D. 1967. Religion and U nderstanding. Oxford: Blackwell.

Plinii, Secundi C. 1992. Naturalis Historia, D. Detlefsen recenuit, vols. I-III. Hildesehim/Zürich/New York: Olms.

Prescott, William Hickling. 1849. H istory of the Conquest of M exico and History of the Conquest of Peru, vol. I, II. London.

Rincón, Carlos. 1990. "Nachwort” zu Diego deLanda. Bericht ausYucatán. Leipzig: Reclam, pp. 221-240.

Rincón, Carlos. 1995. La no simultaneidad de lo simultáneo. Postmodernidad, 
globalización y culturasen América Latina. Bogotá: Editorial Universidad Nacional.

Said, Edward. 1978/21994. Orientalism. New York: Vintage Books.

Subirats, Eduardo. 1994. El continentevacío. La conquista del Nuevo M undo y la conciencia moderna. Madrid: Anaya \& Mario Muchnik.

Thomas, Hugh. 1993/2000. La conquista de M éxico. El encuentro de dos mundos, el choque de dos imperios. México: Planeta.

Todorov, Tzvetan. 1982. La Conquête d'Amérique. La question de l'autre. Paris: Seuil.

Toro, Alfonso de. 2002. "Jenseits von Postmoderne und Postkolonialität. Materialien zu einem Modell der Hybridität und des Körpers als transrelationalem, transversalem und transmedialem Wissenschaftskonzept", en Christof Hamann/Cornelia Sieber (eds.). Räume der H ybridität. Postkoloniale Konzepte in Theorie und Literatur. Hildesheim: Olms, pp. 15-52.

White, Hayden. 1978. Tropi cs of D iscourse: Essays in Cultural Criticism. Baltimore: Johns Hopkins University Press.

Wurm, Carmen. 1996. Doña M arina, La M alinche - Eine historische Figur und ihre literarische Rezeption. Frankfurt am Main: Vervuert.

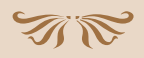

